NBER WORKING PAPER SERIES

INVESTMENT OPTIONS AND THE BUSINESS CYCLE

\author{
Boyan Jovanovic \\ Working Paper 13307 \\ http://www.nber.org/papers/w13307 \\ NATIONAL BUREAU OF ECONOMIC RESEARCH \\ 1050 Massachusetts Avenue \\ Cambridge, MA 02138 \\ August 2007
}

I thank J. Campbell, J. Eaton, R. Gordon, B. Hall, R. Hall, H. Hopenhayn, A. Kurmann, and N. Stokey for comments, V. Tsyrennikov for computations, corrections, comments, and for writing Appendix 1, and the NSF for support. The views expressed herein are those of the author(s) and do not necessarily reflect the views of the National Bureau of Economic Research.

(C) 2007 by Boyan Jovanovic. All rights reserved. Short sections of text, not to exceed two paragraphs, may be quoted without explicit permission provided that full credit, including $\odot$ notice, is given to the source. 
Investment Options and the Business Cycle

Boyan Jovanovic

NBER Working Paper No. 13307

August 2007

JEL No. E3,E44

\section{ABSTRACT}

This paper extends Lucas (1978) to a production economy with two capital goods. It is an RBC model in which each unit of investment requires a new idea, an "option". When options are scarce, new capital is harder to put in place and the value of old capital rises. Thus the stock market and Tobin's Q are negative indexes of intangibles. During a boom, Q rises gradually, as options are used up. Because investment represents an exercise of options, it has an intertemporal substitution tradeoff that is absent in the adjustment-cost model. Equilibrium may be efficient even without markets for knowledge; the stock market may suffice.

Boyan Jovanovic

New York University

Department of Economics

19 W. 4th Street, 6th Floor

New York, NY 10012

and NBER

Boyan.Jovanovic@nyu.edu 


\title{
Investment Options and the Business Cycle
}

\author{
Boyan Jovanovic*
}

July 29, 2007

\begin{abstract}
This paper extends Lucas (1978) to a production economy with two capital goods. It is an RBC model in which each unit of investment requires a new idea, an "option". When options are scarce, new capital is harder to put in place and the value of old capital rises. Thus the stock market and Tobin's $Q$ are negative indexes of intangibles. During a boom, $Q$ rises gradually, as options are used up. Because investment represents an exercise of options, it has an intertemporal substitution tradeoff that is absent in the adjustment-cost model. Equilibrium may be efficient even without markets for knowledge; the stock market may suffice.
\end{abstract}

\section{Introduction}

This paper extends Lucas (1978) to a production economy with two capital goods. One is a traditional capital stock, the other is unimplemented knowledge that I refer to as "investment options." I shall refer to traditional capital as "trees" and to the unexercised options as "seeds." The paper is a specialization of Lucas's model in the sense that the shocks to the trees' productivities are common.

An investment option is a profit opportunity that requires an investment to implement. It is postponable if it is a patented invention, or if it is specific to a firm so that others cannot reduce its value by copying it. A firm has investment options that it may use up immediately, or store for future use. A patent, for instance, represents an investment option that only its holder can implement for a certain number of years. In a sense, even a trademark represents an option to produce a product that no one else can make. Some investment options are protected only by secrecy.

I set up a competitive GE model in which to plant a tree one needs a seed. Seeds are produced by trees that are already planted. The number of trees grows over

*New York University. I thank J. Campbell, J. Eaton, R. Gordon, B. Hall, R. Hall, H. Hopenhayn, A. Kurmann, and N. Stokey for comments, V. Tsyrennikov for computations, corrections, comments, and for writing Appendix 1, and the NSF for support. 
time and, in the absence of the seed constraint on investment, the model would be a standard one-sector $A k$ model with shocks to technology.

The model also embeds in GE and endogenizes what Abel and Eberly (2005) call "growth options." It also relates closely to the GE model of Bilbiie, Ghironi and Melitz (2006) who study the cyclical behavior of entry of producers but in the absence of a seed constraint or of "option-value considerations," as they put it, so that Tobin's $Q$ is always unity. The model has no shocks to the investment technology, but it behaves a bit like models that do have such shocks, such as Greenwood, Hercowitz and Huffman (1987), and Fisher (2005). Investment options are also a focus of the new Keynesian literature (Shleifer 1986), and the strategic delay literature (Chamley and Gale 1994). The paper also relates to models of inventories such as Deaton and Laroque (1992) and Khan and Thomas (2007). The paper's main results are as follows:

(i) Intangibles reduce Q.-Because seeds (i.e., "intangibles") are scarce, the value of planted trees (i.e., firms) and thus Tobin's $Q$, is always above unity. When there are many seeds, their price falls, and if the decline is sharp enough, so then does the price of claims to the output of planted trees. ${ }^{1}$ Contrast that to Hall (2000), where $Q$ is a positive indicator of the stock of intangibles because his intangibles are not embodied in capital but, rather, enter the final-goods production function as a separate input. A natural experiment that distinguishes the two models is a prolonged war during which unimplemented inventions accumulate (some of them being incidental accomplishments of defense-oriented research). My model says that after such a war $Q$ should be low, whereas Hall's model says that it should be high. It turns out that after both world wars, $Q$ in the U.S. was unusually low. Also, measures of intangibles based on aggregate patent applications and trademarks comove negatively with Tobin's $Q$, thus supporting my model.

(ii) $Q$ rising during a boom.-The main difference between the Seeds model and the adjustment-cost model is that during a prolonged boom during which seeds are drawn down and become ever more scarce, Tobin's Q gradually rises. That was indeed what happened during the well-known run-ups of the late ' 20 s and mid-late '90s. For this implication, the ability to store seeds is crucial; the stockpile dwindles as the boom continues. On the other hand, the dwindling supply of seeds during a boom also means that investment declines as the boom continues. Conversely, a rising supply of seeds during a recession means that investment gradually rises and Q gradually falls.

(iii) More volatile Q.- The Seeds model introduces an intertemporal substitution in investment that raises its volatility for given average levels of $Q .{ }^{2}$ By contrast, convex adjustment costs make investment smoother. The concept of investment in

\footnotetext{
${ }^{1}$ This is a GE effect that arises when all firms have more seeds. For any firm that alone receives an additional seed, $Q$ would rise, just as in Abel and Eberly (2005).

${ }^{2}$ By the same token, the ability to postpone investment reduces the model's ability to explain the volatility in $Q$. Intertemporal substitutability raises supply elasticities generally; e.g., of labor
} 
this model is "extensive" investment in new things, and such investment responds more elastically to variations in $Q$; witness, e.g., how closely and elastically venturebacked investment follows the Nasdaq index. ${ }^{3}$ In equilibrium, however, investment is bounded by the available seeds, and this can raise $Q$ to higher levels than in the quadratic-adjustment-cost model.

(iv) Decentralization. - These results obtain in two decentralizations of the planner's optimum. The first has complete markets. The incomplete-market economy has an equilibrium that coincides with the complete-market equilibrium, but it may have other, inefficient equilibria.

The model is similar to ones in which it is not adjustment costs but, rather, liquidity constraints that prevent firms from eliminating the gap between $Q$ and unity. Gomes, Yaron and Zhang (2003) look for a liquidity factor in asset prices, and find one that, however, behaves more procyclically, seeming to pose a greater constraint in the boom, which is consistent with the Seeds model but that they regard as inconsistent with the financial frictions model that they propose.

Section 2 presents the model, section 3 describes a complete-markets decentralization, section 4 an incomplete-markets one. Section 5 reports simulations, and compares the model to the data. Section 6 discusses the effect that intangibles have on stock prices and output, looking at both model and data. Section 7 compares the model to the standard adjustment-cost model. Section 8 tries to tie the model's implications to the behavior of the prices of capital goods and to the skill premium, and to R\&D-based measures of intangibles. Section 9 concludes the paper. Several proofs and extensions are reported in the Appendix.

\section{Model}

The model is that of a growing economy with two types of capital - trees, $k$, and seeds, $S$. A seed represents an option, storable indefinitely, to plant exactly one tree.

Production of fruit.- - Output of fruit is

$$
Y=z k
$$

If $X$ is the number of trees newly planted, $k$ evolves as

$$
k^{\prime}=k+X .
$$

supply in the Lucas and Rapping (1969) model, or of sales in the Deaton and Laroque (1992) and Khan and Thomas (2005) models, and lowers the volatility of equilibrium wages and prices.

${ }^{3}$ The model was originally meant to explain bunching of investment, with IPO waves as the empirical counterpart of such bunching - IPOs are also co-move with the stock market. In a partial equilibrium model, Pastor and Veronesi (2005) argue that investment options are stored during times of high uncertainty, and that once the uncertainty is resolved, firms rush in with IPOs. 
Production of seeds. - Let $S$ denote the stock of seeds. New seeds are produced by existing trees. Each period a tree gives rise to $\lambda$ new seeds, i.e., a total of

$$
\text { new seeds }=\lambda k
$$

Thus seeds grow via a process like learning by doing that takes up no resources.

The planting of trees.-Planting a tree requires a unit of fruit and a seed. Only one tree per seed can be planted, after which the seed is used up. Let $S$ be the stock of seeds and let $X$ be the number of trees planted. Then $S$ evolves as

$$
S^{\prime}=\lambda k+S-X \geq 0 .
$$

Since $X$ is subtracted from the stock, a seed can be used to plant exactly one tree. Thus investment is Leontieff in two inputs, seeds and fruit. Their proportions are equal, an assumption that we shall drop when we get to the empirics, along with the assumption that neither $k$ nor $S$ depreciate. Seeds are storable whereas fruit is not.

Timing.-Investment, $X$, is chosen after the trees produce $z k$ units of fruit and after $\lambda k$ new seeds. From (4), we have

$$
X \leq \lambda k+S
$$

Thus investment is Leontieff in two inputs: seeds and fruit. We shall let investment be reversible. ${ }^{4}$

The income identity. - The cost of planting a tree is, as usual, one unit of fruit. Letting $C$ be the consumption of fruit, the income identity is

$$
z k=C+X
$$

The shocks. - The shocks follow the first-order Markov process: $\operatorname{Pr}\left(z_{t+1} \leq z^{\prime} \mid z_{t}=z\right)=$ $F\left(z^{\prime}, z\right)$, and that $z^{\prime}$ is stochastically increasing in $z$.

Preferences.-For $\sigma>0$ and $\beta<1$, preferences are

$$
E_{0}\left\{\sum_{t=0}^{\infty} \beta^{t} \frac{C_{t}^{1-\sigma}}{1-\sigma}\right\} .
$$

Reducing the state space.-As we shall show formally in Section 2.1, constant returns to scale and the absence of fixed factors allows us to reduce the number of states from three to two: $s \equiv S / k$, and $z$. From (4), the law of motion for $s$ is

$$
s^{\prime}=\frac{\lambda+s-x}{1+x},
$$

\footnotetext{
${ }^{4}$ Sargent (1980) analyzes the implications of the constraint $X \geq 0$. I do not impose this constraint here because the simulations and the data never violate it.
} 

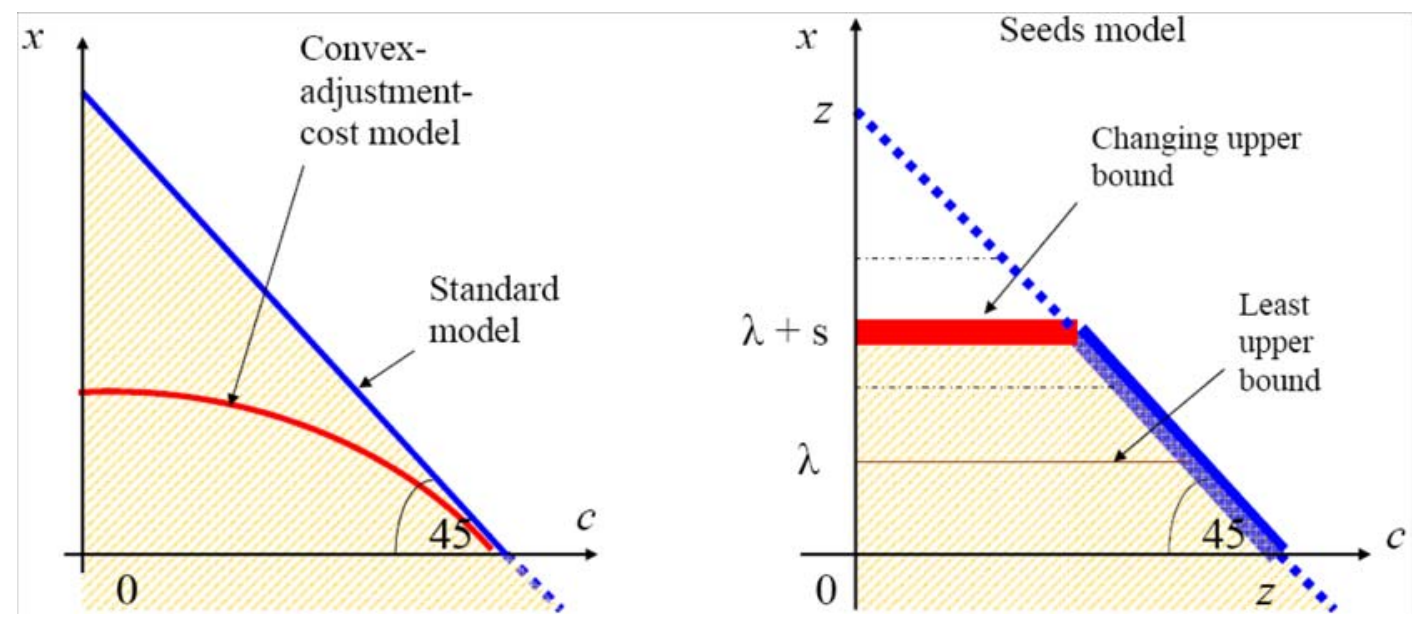

Figure 1: Relation to The COnvex Adjustment-Cost MOdel

implying the inequality constraint

$$
x \leq \lambda+s,
$$

where $x=X / k$. We can express this constraint in terms of the costs. Let

$$
C(x, s)=\frac{\text { investment cost }}{\text { capital stock }}= \begin{cases}x & \text { if } x \leq \lambda+s \\ \infty & \text { otherwise }\end{cases}
$$

denote the cost of investment, in units of fruit.

Before starting the analysis, let us proceed intuitively and compare the Seeds model to two standard models:

(i) The one-sector growth model. - It arises when the inequality in (5) never binds. The latter occurs when $\lambda$ is large enough, e.g., if $\lambda$ exceeds the largest possible $z$. It also occurs, de facto, when the initial stock of seeds, $S_{0}$, is so large that (5) does not come into play for a very long time.

(ii) The adjustment-cost model (ACM).-The ACM is like the Seeds model but instead of (1), (4) and (5), we have the CRS production function

$$
Y=z k-h\left(\frac{X}{k}\right) k, \quad \text { where } h(x)=\frac{1}{\phi}\left(\frac{x}{\lambda^{*}}\right)^{\phi} .
$$

and the states are $(k, z)$ alone. Interpreted in this way, adjustment costs consists of foregone output. In some versions of the ACM, $\phi=2$. Since the ACM has no intertemporal substitution component, the two models are never equivalent except in the special case when the Seeds model has no intertemporal substitution, i.e., when seeds cannot be stored: ${ }^{5}$

\footnotetext{
${ }^{5}$ Depreciation of $S$ is formally introduced when the model is estimated in Section 6 and when comparing the Seeds model to the ACM in Section 7.
} 


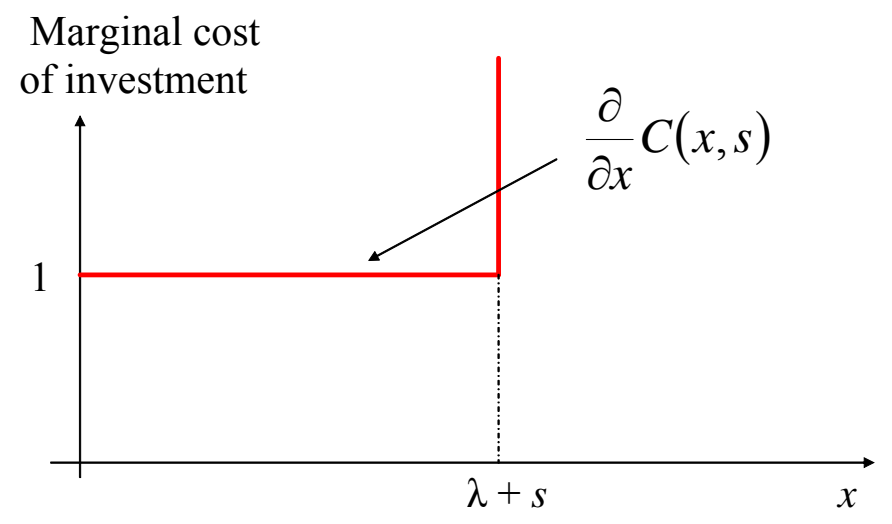

Figure 2: Marginal ADJustment Costs

Proposition 1 If seeds cannot be stored and if

$$
\lambda=\lambda^{*} \text { and } \phi \rightarrow \infty,
$$

the ACM and the Seeds model become the same.

Proof. If seeds cannot be stored, the Seeds model has just one state, namely $z$, and (5) becomes $X \leq \lambda k$. Therefore in (9), the cost cost of investment becomes $C(x, 0)$ in every period. And as $\phi \rightarrow \infty$, the marginal cost of investment in the ACM also converges to $C(x, 0)$ when $\lambda^{*}=\lambda$.

The Proposition is illustrated in Figure 1. In its left panel shows the consumptioninvestment trade-off in the standard model and the convex-adjustment-cost model. In its right panel,the Figure shows the constraint imposed by a particular upper bound on $x$, namely $\lambda+s$. Since $s \geq 0$, investment can never be constrained by any number smaller than $\lambda$, and so that's the tightest constraint on $x$ that can possibly arise. This is the line labeled "least upper bound," and this is the limit reached by both models under the conditions that Proposition 1 describes The position of the constraint will depend on what has been happening earlier. In particular, a "seed crunch" and with it a high value of $Q$ will turn out to be more likely following a prolonged boom caused by a succession of large realizations of $z$. Such realizations are likely to draw $s$ to its minimum level of zero, leading the constraint to be $x \leq \lambda$.

In terms of (9), The marginal adjustment costs, $\frac{\partial}{\partial x} C(x, s)$, are drawn in Figure 2. As in the ACM, costs of adjustment are still convex in $x$, but $x$ also raises future investment costs, an effect absent from the ACM.

The set on which (5) binds. - Consumption is most volatile and investment least volatile when (5) binds. Let $\Delta=\{(s, z) \mid x(s, z)=\lambda+s\}$ be the set of states for which (5) binds. In this region, $X$ cannot respond to $z$ and therefore $C$ moves onefor-one with $z k$ and, hence, is more volatile than in the standard model. True, this 


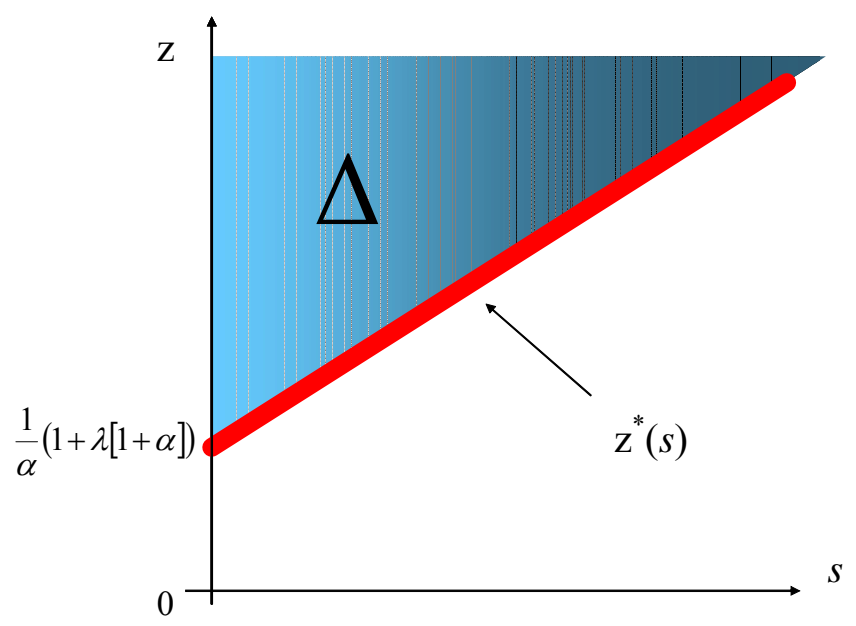

Figure 3: THE SET $\Delta$ WHEN $z$ IS I.I.D.

statement is conditional on $s$, but for $(s, z) \in \Delta, s^{\prime}=0$, and $x^{\prime}=x\left(0, z^{\prime}\right)$. If $(s, z)$ remains in $\Delta$ for more than one period, then in period two and beyond,

$$
x(0, z)=\lambda \text { and } c=z-\lambda \text {. }
$$

where $c=C / k$. The further $z$ is from being a random walk (and it seems to depart substantially from it, see Table 1), the more these rules depart from what the standard model would predict. Even when $z$ is i.i.d., $x$ is increasing in $z$ because a higher $z$ today raises wealth and causes a rise in desired future consumption. Because $x$ is increasing in $z, \Delta$ contains large $z$ values. For $(s, z) \in \Delta, s^{\prime}=0$ so that $x^{\prime}=x\left(0, z^{\prime}\right)$.

\subsection{The planner's problem}

Now we return to the Seeds model as described in (1) through (6). The state is $(k, S, z)$, and the decision, $X$, is constrained by (5). The Bellman eq. is

$$
v(k, S, z)=\max _{X \leq \lambda k+S}\left\{\frac{(z k-X)^{1-\sigma}}{1-\sigma}+\beta \int v\left(k+X, \lambda k+S-X, z^{\prime}\right) d F\right\} .
$$

Lemma 1 A unique solution $v$ to (11) exists, and is is strictly concave in $(k, S)$. Moreover, $X$ is increasing in $S$ and, if $z$ is i.i.d., in $z$.

Proof. ( $i$ ) Existence, uniqueness: Let $T$ denote the operator on the RHS of (11). The operator is a contraction and maps continuous functions $v$ into continuous functions $(T v)$ which, while unbounded, nevertheless meet condition 1d of Alvarez and Stokey (2000), whence existence follows. (ii) Concavity: We shall show that if $\tilde{v}$ is concave then $T \tilde{v}$ is strictly concave. Let $0 \leq \alpha \leq 1$. The constraint (5) is convex 
and its boundary is linear in $S$ and $k$. Therefore if $X_{1}$ is feasible and optimal for the state $\left(k_{1}, S_{1}\right)$ and $X_{2}$ is feasible and optimal for $\left(k_{2}, S_{2}\right)$, then $X_{\alpha} \equiv \alpha X_{1}+(1-\alpha) X_{2}$ is feasible, though not necessarily optimal for $\left(\alpha k_{1}+(1-\alpha) k_{2}, \alpha S_{1}+(1-\alpha) S_{2}\right)$. Therefore if $0<\alpha<1$

$$
\begin{aligned}
T \tilde{v}\left(\alpha k_{1}+(1-\alpha) k_{2}, \alpha S_{1}+(1-\alpha) S_{2}\right) & \geq \frac{\left(z k-X_{\alpha}\right)^{1-\sigma}}{1-\sigma}+\beta \int \tilde{v}\left(k+X_{\alpha}, \lambda k+S-X_{\alpha}, z^{\prime}\right) d F \\
& >\alpha T \tilde{v}\left(k_{1}, S_{1}\right)+(1-\alpha) T \tilde{v}\left(k_{2}, S_{2}\right)
\end{aligned}
$$

Therefore the operator transforms weakly into strictly concave functions. Therefore, the operator being a contraction, its unique fixed point $v$ is strictly concave. (iii) Properties of $X$ : The FOC is

$$
\xi(X, S) \equiv-(z k-X)^{-\sigma}+\beta \int \frac{d}{d X} v\left(k+X, \lambda k+S-X, z^{\prime}\right) d F=0
$$

(Once-differentiability of $v$ will be proved later) We have dropped $k$ and $z$ from the arguments of $\xi$ as they play no role in the proof. We now argue in 3 steps: $(A)$ If a function of one variable $H$ is twice differentiable with $H^{\prime \prime}<0$, then

$$
\frac{\partial}{\partial S}\left(\frac{\partial}{\partial X} H[\lambda k+S-X]\right)=-H^{\prime \prime}(\cdot)>0
$$

Therefore, concavity of $v$ in $S$ alone implies $\frac{\partial}{\partial S} \frac{d v}{d X}\left(=-\frac{\partial^{2} v}{\partial S^{2}}\right)>0$ (the monotonicity results do not require the second derivatives) earlier, under ( $i i)$ we showed that concavity of $v$ in $(k, S)$ implies concavity of $v$ in $X$ holding $(k, S)$ fixed - i.e., that $\frac{d^{2} v}{d X^{2}}<0$ and $(B)$ Therefore $\xi_{X}<0$ and $\xi_{S}>0$. And, when $z$ is i.i.d., $\xi_{z}=\sigma(z k-X)^{-1-\sigma}$. (C) Therefore $\frac{\partial X}{\partial S}=-\frac{\xi_{S}}{\xi_{X}}>0$, and when $z$ is i.i.d., $\frac{\partial X}{\partial z}=-\frac{\xi_{z}}{\xi_{X}}>0$.

Reducing the state space.-The following result allows us to reduce the state space to just $(s, z)$ :

Lemma 2 For $\sigma \neq 1, v$ is of the form

$$
v(k, S, z)=w(s, z) k^{1-\sigma},
$$

where $w(s, z)=v(1, s, z)$, and where $w$ satisfies

$$
w(s, z)=\max _{x \leq \lambda+s}\left\{\frac{(z-x)^{1-\sigma}}{1-\sigma}+(1+x)^{1-\sigma} \beta \int w\left(\frac{\lambda+s-x}{1+x}, z^{\prime}\right) d F\right\} .
$$

Moreover, $v$ and $w$ are of the same sign as $1-\sigma$.

The proof (not reported) substitutes the desired functional form for $v$ on the RHS of (11), and verifies that the same functional form emerges on the LHS. The case $\sigma=1$ is covered separately below. Similar results are in Alvarez and Stokey (2000). 
Corollary 1 A unique solution $w$ to (13) exists that is increasing and concave in $s$.

Proof. Existence: Since a unique $v$ exists, $w(s, z)=v(k, S, z) k^{-(1-\sigma)}$ is the unique solution for $w$. Increasing: In (8), a rise in $s$ relaxes the constraint on $x$. Moreover, if one inserts on the RHS of (13) a function $w$ that increases in $s$, evidently the property is preserved. Concave: The concavity of $v(k, S, z) k^{-(1-\sigma)}$ in $S$ for fixed $k$ implies that $w$ is concave in $s$.

Corollary 2 The policy $x(s, z)$ is increasing in $s$ and, if $z$ is i.i.d., increasing in $z$.

Proof. All changes in $s \equiv S / k$ can be interpreted as changes in $S$ for a given $k$. By Lemma $2, X$ is, for all $k$, increasing in $S$. For fixed $k$, a rise in $S$ implies a rise in $s$ and in $x$. The claim about $z$ follows at once from Lemma 2 .

Lemma 3 w is strictly increasing in $z$.

Proof. The constraint set $x \in[-1, z]$ is stochastically increasing in $z$. Since $z^{\prime}$ is stochastically increasing in $z$, for any function $w(s, z)$ increasing in $z^{\prime}$, the second term on the RHS of (13) is increasing in $z$. Moreover, since $C \geq 0$, the first term on the RHS of (13) is strictly increasing in $z$.

Lemma 4 w is differentiable with respect to $s$, with derivative

$$
w_{s}=\frac{1}{1+\lambda+s}\left([1-\sigma] w-(1+z)[z-x]^{-\sigma}\right)>0
$$

for all $(s, z)$.

The proof is in Appendix 1; it follows the proof of Proposition 2 of Lucas (1978) but is complicated by the constraint (8).

Note that the term $(1-\sigma) w$ is positive for all $\sigma \neq 1$ because for $\sigma>1, w<0$.

Lemma 5 The optimal policy $x(s, z)$ satisfies

$$
1-\beta \int\left(\frac{(1+x)}{z-x}\right)^{-\sigma}\left[\left(z^{\prime}-x^{\prime}\right)^{-\sigma}\left(1+z^{\prime}\right)+\lambda w_{s}^{\prime}\right] d F\left\{\begin{array}{ll}
=0 & \text { if } s^{\prime}>0 \\
\leq 0 & \text { if } s^{\prime}=0
\end{array}\right. \text {. }
$$

Proof. By Lemma 2, $v$ is differentiable w.r.t. $k$, and if $w$ is differentiable w.r.t. $s$, so is $v$ w.r.t. $S$. Then the FOC is

$$
C^{-\sigma}-\beta \int\left(v_{k}-v_{S}\right) d F \leq 0
$$


with equality if $S^{\prime}>0$. We have

$$
v(k, S, z)=\max _{S^{\prime}}\left\{\frac{\left(z k+S^{\prime}-\lambda k-S\right)^{1-\sigma}}{1-\sigma}+\beta \int v\left(k+\lambda k+S-S^{\prime}, S^{\prime}, z^{\prime}\right) d F\right\} .
$$

Since $S$ does not enter the constraint $S^{\prime} \geq 0$, the envelope theorem gives us

$$
v_{S}=-C^{-\sigma}+\beta \int v_{k} d F
$$

and

$v_{k}=(z-\lambda) C^{-\sigma}+(1+\lambda) \beta \int v_{k} d F=(z-\lambda) C^{-\sigma}+(1+\lambda)\left(v_{S}+C^{-\sigma}\right)=(1+\lambda) v_{S}+(1+z) C^{-\sigma}$

But by Lemma $2, v(k, S, z)=w\left(\frac{S}{k}, z\right) k^{1-\sigma}$ so that

$$
v_{k}=(1-\sigma) w k^{-\sigma}-s w_{s} k^{-\sigma} \quad \text { and } \quad v_{S}=w_{s} k^{-\sigma}
$$

Now, from $(17), v_{k}=(1+\lambda) v_{S}+(1+z) C^{-\sigma}$, so that the FOC becomes

$$
C^{-\sigma}-\beta \int\left(\lambda v_{S}^{\prime}+(1+z) C^{\prime-\sigma}\right) d F \leq 0
$$

But $v_{S}=w_{s} k^{-\sigma}$ and the above equation then reads

$$
\begin{aligned}
0 & \geq(z-x)^{-\sigma} k^{-\sigma}-\beta \int\left(\lambda w_{s}^{\prime}\left(k^{\prime}\right)^{-\sigma}+\left(1+z^{\prime}\right)\left(z^{\prime}-x^{\prime}\right)^{-\sigma}\left(k^{\prime}\right)^{-\sigma}\right) d F \\
& =\left(\frac{z-x}{1+x}\right)^{-\sigma}-\beta \int\left(\lambda w_{s}^{\prime}+\left(1+z^{\prime}\right)\left(z^{\prime}-x^{\prime}\right)^{-\sigma}\right) d F
\end{aligned}
$$

from which (15) follows.

Let

$$
z^{*}(s)=\inf \{z \mid(z, s) \in \Delta\}
$$

be the lower boundary of $\Delta$, i.e., the line drawn in Figure 3. We then can show the following:

Proposition 2 If $z \sim F(z)$ is i.i.d., then

$$
z^{*}(s)=\frac{1+(1+\alpha)(\lambda+s)}{\alpha},
$$

where $\alpha$ is the constant:

$$
\alpha=\left(\beta \int \frac{\lambda(1-\sigma) w\left(0, z^{\prime}\right)-\left(1+z^{\prime}\right)\left(z^{\prime}-x\left[0, z^{\prime}\right]\right)^{-\sigma}}{1+\lambda} d F\left(z^{\prime}\right)\right)^{1 / \sigma} .
$$


Proof. From (15) and from a one-period update of (14) we have

$\beta \int\left(\frac{1+x}{z-x}\right)^{-\sigma} \frac{\lambda(1-\sigma) w^{\prime}-\left(1+s^{\prime}\right)\left(1+z^{\prime}\right)\left(z^{\prime}-x^{\prime}\right)^{-\sigma}}{1+\lambda+s^{\prime}} d F\left\{\begin{array}{l}=1 \text { if } s^{\prime}>0 \\ \geq 1 \text { if } s^{\prime}=0\end{array}\right.$,

i.e.,

$$
\beta \int \frac{\lambda(1-\sigma) w^{\prime}-\left(1+s^{\prime}\right)\left(1+z^{\prime}\right)\left(z^{\prime}-x^{\prime}\right)^{-\sigma}}{1+\lambda+s^{\prime}} \begin{cases}=\left(\frac{1+x}{z-x}\right)^{\sigma} & \text { if } s^{\prime}>0 \\ \geq\left(\frac{1+x}{z-x}\right)^{\sigma} & \text { if } s^{\prime}=0\end{cases}
$$

i.e.,

$$
\alpha \begin{cases}=\frac{1+x}{z-x} & \text { if } s^{\prime}>0 \\ \geq \frac{1+x}{z-x} & \text { if } s^{\prime}=0\end{cases}
$$

On the other hand, if $x$ is constrained and held constant at $\lambda+s$ as $z$ varies, the RHS is decreasing in $z$. Large $z$ 's make the inequality strict. We find the smallest $z$ that will allow strict equality at $x=\lambda+(1+\lambda) s$. Setting it at equality we have $1+\lambda+s=\alpha(z-\lambda-s)$, from which (19) follows. Moreover, for $z=z^{*}(s)$ at $s^{\prime}=0$ so that $x^{\prime}=x\left(0, z^{\prime}\right)$, and $w^{\prime}=w\left(0, z^{\prime}\right)$, which yields $(20)$.

On $\Delta$, only $Q$ responds to changes in $z ; x$ does not, and therefore $s^{\prime}=\lambda$ is also unchanged. Therefore shocks to output today have no effect on output in any future period. Since $\Delta$ contains mainly boom states the model thus implies that the persistence of output shocks is lower in booms. Moreover, in this case where $z$ is i.i.d., changes in $Q$ will not forecast output. This matches the finding of Henry et al. (2005) that the stock market predicts growth better in recessions than in booms.

When $z$ is serially correlated, the boundary of $\Delta$ is no longer linear but $\Delta$ retains a shape similar to that portrayed in Figure 3: $z^{*}(s)$ still solves (19) in which $\alpha$ is replaced by

$$
\alpha(z)=\left(\beta \int \frac{\lambda(1-\sigma) w\left(0, z^{\prime}\right)-\left(1+s^{\prime}\right)\left(1+z^{\prime}\right)\left(z^{\prime}-x\left[0, z^{\prime}\right]\right)^{-\sigma}}{1+\lambda+s^{\prime}} d F\left(z^{\prime}, z\right)\right)^{1 / \sigma} .
$$

While $x$ is less volatile on $\Delta$, to achieve a given growth rate, $x$ must make up for its low mean on $\Delta$ with a higher mean off of $\Delta$, which introduces a force towards bimodality in the distribution of $x$ and a higher volatility of $x .^{6}$

\footnotetext{
${ }^{6}$ This section relates to Yorukoglu (2000) who studied the relation between income and the variety of goods and who also had two regimes for consumption.
} 


\section{Decentralization 1: Markets for trees and seeds}

Assume that a market for seeds exists. If seeds are ideas or claims to ideas, this is not so unrealistic. Serrano (2006) finds that 18 percent of patents granted to small inventors are traded at least once in their lives, and that the citations-weighted percentage is even higher. Large firms also often sell their patents and enter into patent-sharing agreements with one another. Takeovers play a part in achieving transfers of intellectual capital; this is a fairly thick market in which Microsoft and Pfizer, e.g., have been highly active. A firm can be said to sell seeds when it spins off some activity, or when it hires people at wages that include a negative compensating differential for the value that its workers will draws from the experience gained; such a market is modeled, e.g., by Prescott and Boyd (1987), Chari and Hopenhayn (1991), Franco and Filson (forthcoming), and Chatterjee and Rossi-Hansberg (2007). An example of employees walking out with seeds is Xerox in the 70's - it had inventions that it was unable or unwilling to implement and that were later marketed by its former employees.

Prices. - Let $p$ be the price of seeds, and $q$ the price of a planted tree without a claim on its current-period outputs of fruit and seeds.

Firms. - Firms last one period. A firm pays its net sales of fruit, $z k-X$, in dividends every period, plus any profits it makes on buying and selling trees and seeds. A firm enters a period with the bundle $(k, S)$. It produces $z k$ units of fruit and $\lambda k$ seeds and it plants $X$ trees. At the end of the period, it sells its holdings $\left(k+X, S^{\prime}\right)$ to the public and to next generation of firms at the price vector $(q, p)$, pays all its profits out in dividends to its shareholders, and liquidates. Its profits are

$$
\begin{aligned}
\pi(k, S, z) & \equiv z k-X+q(k+X)+p S^{\prime} \\
& =(z+q) k+p(S+\lambda k)+(q-[1+p]) X
\end{aligned}
$$

after substitution from (4) for $S^{\prime}$.

No arbitrage.-A negative $X$ would entail selling off $X$ trees and $X$ seeds that those trees embody at a price of $1+p \cdot{ }^{7}$ Thus we have the no-arbitrage condition ${ }^{8}$

$$
q=1+p,
$$

which implies that

$$
\pi(k, S, z)=(z+p \lambda+q) k+p S .
$$

The first three terms represent rents from trees, and the fourth rents from seeds.

Households.- Households own trees and seeds separately. Ownership of a tree delivers an end-of-period income $z+p \lambda+q$, and ownership of a seed delivers $p$.

\footnotetext{
${ }^{7}$ This happens, e.g., when a company sells off a division, or when it is acquired.

${ }^{8}$ This condition would hold even if aggregate investment is nonnegative; an individual firm could have $X<0$ without affecting aggregates.
} 
Ownership lapses after one period. The household's budget constraint therefore reads

$$
C+p\left(S^{\prime}-S\right)+q\left(k^{\prime}-k\right)=z k+p \lambda k .
$$

Equilibrium.-When the households' and firms' plans coincide, (2) and (4) hold, and when we use, the LHS of (23) becomes

$$
\begin{aligned}
C+p(\lambda k-X)+q X & =C+X+p \lambda k \quad \text { using }(21) \\
& =z k+p \lambda k \quad \text { using }(6),
\end{aligned}
$$

which coincides with the RHS of (23). Since the firm's problem does not determine $X$ (provided that [21] holds), we shall derive the decision rules for $X$ from the household's problem.

The household's Bellman eq.-We shall assume that $p=p(s, z)$ does not depend on $k$, in which case (21) implies that $q(s, z)$ also does not depend on $k$. The household's personal state is $(k, S)$, and it takes the aggregate state $(\mathbf{k}, \mathbf{S}, z)$ and the aggregate laws of motion for $(k, S)$ which depend on the decision rules of other households as given. The household's Bellman equation is

$V(k, S, \mathbf{k}, \mathbf{S}, z)=\max _{k^{\prime}, S^{\prime} \geq 0}\left\{U\left(z k+p \lambda k-p\left[S^{\prime}-S\right]-q\left[k^{\prime}-k\right]\right)+\beta \int V\left(k^{\prime}, S^{\prime}, \mathbf{k}^{\prime}, \mathbf{S}^{\prime}, z^{\prime}\right) d F\right\}$,

where

$$
p=p\left(\frac{\mathbf{S}}{\mathbf{k}}, z\right), \quad q=1+p\left(\frac{\mathbf{S}}{\mathbf{k}}, z\right), \quad \mathbf{k}^{\prime}=\hat{k}^{\prime}(\mathbf{k}, \mathbf{S}, \mathbf{k}, \mathbf{S}, z), \quad \mathbf{S}^{\prime}=\hat{S}^{\prime}(\mathbf{k}, \mathbf{S}, \mathbf{k}, \mathbf{S}, z)
$$

and where $(\hat{k}, \hat{S})$ are functions that the household takes as given but that in equilibrium will have to coincide with the household's policy rules - hence a fixed-point exercise in $(\hat{k}, \hat{S})$ is needed at the end.

Lemma 6 If equilibrium exists, it is the same as the planner's optimum.

Proof. Since the household consumes all the output, equilibrium is optimal if and only if, for all $(k, S, z)$,

$$
V(k, S, k, S, z)=v(k, S, z) .
$$

Since the planner's solution maximizes the representative household's consumption, $V \leq v$ for all states. But when $(21)$ holds, then any $\left(C, k^{\prime}, S^{\prime}\right)$ that the planner can feasibly choose is also feasible to the household: Let $C^{h}$ be the household's choice $C^{p}$ the planner's choice: Plugging the planner's choices $\left(k^{\prime}, S^{\prime}\right)$ into the household's budget constraint, $C^{h}=z k+p \lambda k-\left(p\left[S^{\prime}-S\right]+q\left[k^{\prime}-k\right]\right)=z k+p \lambda k-$ $\left(p\left[\lambda k-X^{p}\right]+q X^{p}\right)=z k-X^{p}=C^{p}$. Then $V \geq v$ and therefore (25) holds. 
The household is not constrained by (4), so that the two first-order conditions must both hold with equality:

$$
k^{\prime}:-q U^{\prime}(C)+\beta \int V_{1} d F=0
$$

and

$$
S^{\prime}:-p U^{\prime}(C)+\beta \int V_{2} d F=0 .
$$

Efficiency of the equilibrium.- - Subtracting (27) from (26) and applying (21) yields

$$
-U^{\prime}(C)+\beta \int\left(V_{1}-V_{2}\right) d F
$$

This implies (26) is $V_{1}=v_{1}$ and if $V_{2}=v_{2}$. In that case prices would coincide with marginal social values of $(k, S)$, because the envelope theorem applied to (24) gives $V_{1}=(z+p \lambda+q) U^{\prime}(C)$ and $V_{2}=p U^{\prime}(C)$, i.e.,

$$
p=\beta \int \frac{U^{\prime}\left(C^{\prime}\right)}{U^{\prime}(C)} p^{\prime} d F\left(z^{\prime}, z\right)
$$

and

$$
\begin{aligned}
q & =\beta \int \frac{U^{\prime}\left(C^{\prime}\right)}{U^{\prime}(C)}\left(z^{\prime}+p^{\prime} \lambda+q^{\prime}\right) d F\left(z^{\prime}, z\right) \\
& =\lambda p+\beta \int \frac{U^{\prime}\left(C^{\prime}\right)}{U^{\prime}(C)}\left(z^{\prime}+q^{\prime}\right) d F\left(z^{\prime}, z\right)
\end{aligned}
$$

where $p$ and $q$ are evaluated at $\left(\frac{S}{k}, z\right)$, and $V_{1}$ and $V_{2}$ at $(k, S, k, S, z)$.

Calculating $q$ and $p$.-Optimum and equilibrium are the same, and therefore $p$ must equal the marginal social value of a seed:

$$
p(s, z)=\frac{1}{U^{\prime}(C)} v_{S}=(z-x)^{\sigma} w_{s}(s, z) .
$$

because $\frac{1}{U^{\prime}(C)}=\frac{(z-x)^{\sigma}}{k^{-\sigma}}$ and $v_{S}=\frac{1}{k} w_{s}(s, z) k^{1-\sigma}$. Now we can finally prove the result on the relation between seeds and $q$ :

Proposition $3 p(s, z)$ and, hence, $q(s, z)$ are decreasing in $s$.

Proof. By Corollary 1, $w$ is concave in $s$ which means that $w_{s}$ is decreasing in $s$. By Corollary 2, $x$ is increasing in $s$ so that $(z-x)^{\sigma}$ is decreasing in $s$. Thus the claim holds for $p$ and, by (21) it also holds for $q$.

Thus the ability to store seeds reduces the model's ability to explain a level of $Q$ above unity. Allowing for intertemporal substitution therefore reduces the level of 
$Q$ and it also reduces the model's ability to explain the volatility in $Q$, for the same reason that in models of storage such as Deaton and Laroque (1992), the storage technology reduces expected fluctuations in the price of the commodity: Models of competitive storage imply $E_{t}\left(p_{t+1}\right) \leq \frac{1+r}{1-\delta} p_{t}$, where $r$ is the rate of interest and $\delta$ the depreciation rate or carrying cost.

Book value.-We shall measure the "replacement" cost of the firm by the stock of its tangible capital, $k$, even though the true replacement cost is $(1+p) k$. This is because until recently a U.S. firm could, and would, treat its R\&D as an expense, and deductible from the firms taxable income.

Measured Tobin's Q.- The firm's investment activity yields it zero profits. The income generated by the trees in the ground is $z k+p \lambda$ and we shall think of it as the firm's earnings or its dividend. Then the "ex-dividend" value of its assets $(k, S)$ is $q k+p S$, or per tree it is

$$
Q^{a}(s, z) \equiv q+p s .
$$

This is what we shall use for $Q$ in the simulated model in Figures 4 and 5, and in the regression (47). We may think of $q$ as the firm's marginal $Q$ because that is the cost of a planted tree. Thus measured $Q$ exceeds marginal $Q$.

\section{Decentralization 2: Market for firm shares only}

This section simply assumes that the market for seeds is closed and that, while each firm's state $(k, S, z)$ is public information, separate markets for $k$ and $s$ do not exist. It would of course be better to model the friction that causes the market for seeds to have zero transactions, but this would complicate things. So, let us assume that only $(k, S)$ bundles trade in the form of shares of firms. We use the recursive equilibrium concept of Mehra and Prescott (1980) extended to a growing economy, as done in Jovanovic (2006).

Suppose that firms' shares trade but that seeds and trees do not trade separately. Seeds then have to be stored by the firms that produced them, and the representative firm holds the tree-seed bundle $(k, S)$ under its roof. The household can own a claim on the dividends paid by such a firm and no other assets exist. Therefore this decentralization has just two markets: A market for output, and a market for firms' shares. Since the number of date- $t$ goods (consumption, capital, and seeds) is three, the number of goods exceeds the number of markets, and we cannot be sure that a recursive competitive equilibrium is optimal.

Assume a continuum of firms of measure one and an equal number of households. Equilibrium then requires that each household hold exactly one share. Firms pay $(z-x[s, z]) k$ dividends in state $(k, s, z)$, and households take firms' policies $x(s, z)$ as given. 


\subsubsection{The household's decision problem}

With $n$ shares, a household's wealth is the current dividend, $(z-x) k$ plus the exdividend value of his holdings, $\hat{Q}(s, z) k n$. This wealth is spent on consumption and on future holdings of shares $\hat{Q}(s, z) k n^{\prime}$. Thus $\hat{Q} k n^{\prime}+C=([z-x] k+\hat{Q} k) n$, or after dividing through by $k$,

$$
\hat{Q} n^{\prime}+c=(z-x+\hat{Q}) n
$$

so that

$$
c=(z-x) n+\hat{Q}\left(n-n^{\prime}\right)
$$

where $x$ is given to the household. The household takes the aggregate law of motion of $k^{\prime}(s, z) x(s, z)$ and $s^{\prime}(s, z)$ as given. His state is $(k, n, s, z)$, and, with some of the arguments $(s, z)$ dropped from the notation, his Bellman equation then is

$V(k, n, s, z)=\max _{n^{\prime}}\left\{\frac{\left((z-x[s, z]) n+\hat{Q}(s, z)\left(n-n^{\prime}\right)\right)^{1-\sigma} k^{1-\sigma}}{1-\sigma}+\beta \int V\left(k^{\prime}(s, z), n^{\prime}, s^{\prime}, z^{\prime}\right) d F\right\}$.

Deriving the pricing equation.-As in the planner's problem, $V(k, n, s, z)=W(n, s, z) k^{1-\sigma}$, where

$$
W(n, s, z)=\max _{n^{\prime}}\left\{\begin{array}{c}
\frac{\left([z-x(s, z)] n+\hat{Q}(s, z)\left(n-n^{\prime}\right)\right)^{1-\sigma}}{\beta(1+x[s, z])^{1-\sigma} \int^{1-\sigma} W\left(n^{\prime}, s^{\prime}[s, z], z^{\prime}\right) d F} \\
\beta .
\end{array}\right.
$$

The derivative of $W$ with respect to $n$, call it $W_{n}$, exists for much the same reasons that $w_{s}$ does. Equilibrium requires that $n^{\prime}(1, s, z)=1$. At equilibrium, the first-order condition is

$$
(z-x[s, z])^{-\sigma} \hat{Q}(s, z)=\beta(1+x[s, z])^{1-\sigma} \int W_{n}\left(1, s^{\prime}[s, z], z^{\prime}\right) d F .
$$

The envelope theorem then implies

$$
W_{n}(1, s, z)=(z-x[s, z])^{-\sigma}[z-x(s, z)+\hat{Q}(s, z)] .
$$

Updating, substituting into (33), and dividing by $(z-x)^{-\sigma}$ gives our version of the Lucas (1978) pricing formula

$$
\hat{Q}(s, z)=\beta(1+x[s, z]) \int M\left(s, s^{\prime}, z, z^{\prime}\right)\left(z^{\prime}-x\left[s^{\prime}(s, z), z^{\prime}\right]+\hat{Q}\left(s^{\prime}[s, z], z^{\prime}\right)\right) d F
$$

where

$$
M\left(s, s^{\prime}, z, z^{\prime}\right) \equiv\left(\frac{[1+x(s, z)]\left(z^{\prime}-x\left[s^{\prime}(s, z), z^{\prime}\right]\right)}{z-x(s, z)}\right)^{-\sigma}
$$

is the MRS in consumption between today and tomorrow. 


\subsubsection{The firm's decision problem}

Since markets for $s$ do not exist, the firm's only decision is $x$. Let us use bold letters to denote aggregate states and decisions $\mathbf{x}(\mathbf{s}, z)$ and $\mathbf{s}^{\prime}(\mathbf{s}, z)$. Let $P$ denote the cumdividend price of $1 / k$ 'th of the representative firm, i.e., the price of the tuple $(1, s)$. Equilibrium is efficient if $P=v_{k}+s v_{S}$, with $v$ defined in (11). The functional equation (in units of the consumption good) for its cum-dividend price per unit of $k$ is

$$
P(\mathbf{s}, s, z)=\max _{x}\left(z-x+\beta(1+x) \int M\left(\mathbf{s}, \mathbf{s}^{\prime}, z, z^{\prime}\right) P\left(\mathbf{s}^{\prime}[\mathbf{s}, z], s^{\prime}, z\right) d F\right)
$$

Writing $P$ in this way implies that $s$ is public information $s$ even when it differs from s. I.e., (36) assumes that $(s, \mathbf{s})$ is a sufficient statistic for the how the market values the firm. If the market did not know a firm's $s$, it would try to guess $s$ from the firm's choice of $x$, and incentive constraints would be needed to accompany the problem in (36). Thus the seeds market does not exist for reasons other than imperfect information about $s$.

In equilibrium,

1. All firms must choose the same $x$, and so we ask that in state $(s, z)=(\mathbf{s}, z)$, the firm will behave like other firms. That is, at the fixed point for $P$, the RHS of (36) is maximized by $x(s, s, z)=\mathbf{x}(s, z)$. This would imply that $s^{\prime}=\frac{\lambda+s-x(s, s, z)}{1+x(s, s, z)}=\mathbf{s}^{\prime}(s, z)=\frac{\lambda+s-\mathbf{x}(s, z)}{1+\mathbf{x}(s, z)}$.

2. For all $(s, z)$, the maximized value of the firm must equal the value that the shareholders hold:

$$
P(\mathbf{s}, s, z)=z-x(\mathbf{s}, s, z)+(1+x(\mathbf{s}, s, z)) \hat{Q}(\mathbf{s}, z) .
$$

In fact, property 1 implies property 2 as one can deduce by setting $x(s, s, z)=$ $\mathbf{x}(s, z)$ for all $(s, z)$ so that $s^{\prime}=\mathbf{s}^{\prime}$, in which case substitution from (37) into (36) makes it identical to (34). Thus it suffices to show that property 1 holds. Recall that

$U(C)=\frac{c^{1-\sigma}}{1-\sigma}$ so that $U^{\prime}\left(C^{\prime}\right) / U^{\prime}(C)=\left[(1+x)\left(z^{\prime}-x^{\prime}\right) /(z-x)\right]^{-\sigma}$. Then, evaluated at $x=\mathbf{x}$, the FOC in (36), calculated by solving

$P(\mathbf{s}, s, z)=\max _{s^{\prime}}\left\{z-\hat{x}\left(s^{\prime}, s\right)+\beta\left(1+\hat{x}\left[s^{\prime}, s\right]\right) \int M\left(\mathbf{s}, \mathbf{s}^{\prime}[\mathbf{s}, z], z, z^{\prime}\right) P\left(\mathbf{s}^{\prime}[\mathbf{s}, z], s^{\prime}, z^{\prime}\right) d F\right\}$

where

$$
\hat{x}\left(s^{\prime}, s\right)=\frac{\lambda+s-s^{\prime}}{1+s^{\prime}},
$$

and does not depend on the firm's action. 
Differentiability of P.-Similar to the proof of Lemma 4 we can establish that $P_{s}(\mathbf{s}, s, z) \equiv \frac{\partial}{\partial s} P(\mathbf{s}, s, z)$ exists everywhere. Since

$$
\frac{\partial \hat{x}}{\partial s^{\prime}}=\frac{\partial(1+\hat{x})}{\partial s^{\prime}}=\frac{\partial}{\partial s^{\prime}}\left(\frac{1+\lambda+s}{1+s^{\prime}}\right)=-\frac{1+x}{1+s^{\prime}}
$$

the derivative w.r.t. $s^{\prime}$ is $\frac{1+x}{1+s^{\prime}}-\beta \frac{1+x}{1+s^{\prime}} \int M^{\prime} P^{\prime} d F+(1+x) \beta \int M^{\prime} P_{s}^{\prime} d F \leq 0$, with an exact equality if $s^{\prime}>0$. The term $(1+x)$ cancels, and so the FOC to the problem (38) is

$$
1-\beta \int M^{\prime} P^{\prime} d F+\left(1+s^{\prime}\right) \beta \int M^{\prime} P_{s}^{\prime} d F\left\{\begin{array}{ll}
=0 & \text { if } s^{\prime}>0 \\
\leq 0 & \text { if } s^{\prime}=0
\end{array},\right.
$$

Efficiency.-Here $P$ is the cum-dividend price of one- $k$ 'th of the firm in current consumption units. Per unit of its $k$, a firm is a package of $(1, s)$ units of $(k, S)$. Therefore, efficiency would appear to require that $P=\frac{1}{U^{\prime}}\left(v_{k}+s v_{S}\right)$. In what follows we let $x(s, z)$ denote the planner's optimal policy, and $s^{\prime}(s, z)=\frac{\lambda+s-x(s, z)}{1+x(s, z)}$.

The next claim states that if the representative firm used the planner's policy, its market value would equal the marginal social value of the bundle $(k, S)$ :

\section{Lemma 7}

$$
P(s, s, z)=P
$$

where $P$ is given in (36).

Proof. Updating (41) by a period we have $P\left(s^{\prime}[s, z], s^{\prime}, z^{\prime}\right)=(1-\sigma)\left(z^{\prime}-x\left[s^{\prime}, z^{\prime}\right]\right)^{\sigma} w\left(s^{\prime}, z^{\prime}\right)$. Substituting into the RHS of (36), the latter becomes

$$
\begin{aligned}
& z-x(s, z)+\beta(1+x[s, z]) \int M\left(s, s^{\prime}, z, z^{\prime}\right)(1-\sigma)(z-x[s, z])^{\sigma} w\left(s^{\prime}[s, z], z^{\prime}\right) d F \\
= & z-x+(1-\sigma) \beta \frac{(1+x)^{1-\sigma}}{(z-x)^{-\sigma}} \int w\left(s^{\prime}, z^{\prime}\right) d F \quad \text { in view of }(35) \\
= & (1-\sigma)(z-x[s, z])^{\sigma} w(s, z) \\
= & P(s, s, z), \text { as claimed in }(41) .
\end{aligned}
$$

The previous lemma is, however, conditional on the assumption that the representative firm uses the planner's policy, i.e., that

$$
x(s, s, z)=x(s, z) .
$$

Next we shall show that (42) does hold if (41) does.

Lemma 8 If $P$ satisfies (41), then (42) holds. 
Proof. If (42) holds, the firm's FOC, (40), must coincide with the planner's FOC, (15). In view of (35), LHS of (40) can be written as $1-\beta \int\left(\frac{(1+x)\left(z^{\prime}-x^{\prime}\right)}{z-x}\right)^{-\sigma}\left(P^{\prime}-\left[1+s^{\prime}\right] P_{s}^{\prime}\right) d F$. This is the same as the LHS of (15) if

$$
\left(z^{\prime}-x^{\prime}\right)^{-\sigma}\left(P^{\prime}-\left[1+s^{\prime}\right] P_{s}^{\prime}\right)=\left[\left(z^{\prime}-x^{\prime}\right)^{-\sigma}\left(1+z^{\prime}\right)+\lambda w_{s}^{\prime}\right]
$$

i.e., if

$$
1+z+\frac{\lambda w_{s}}{(z-x)^{-\sigma}}=P-(1+s) P_{s}
$$

Now applying the envelope theorem in (38) and noting that, since $\hat{x}\left(s^{\prime}, s\right)=\frac{\lambda+s-s^{\prime}}{1+s^{\prime}}$, $\frac{\partial \hat{x}}{\partial s}=\frac{1}{1+s^{\prime}}=\frac{1+x}{1+\lambda+s}$, gives

$$
\begin{aligned}
P_{s} & =\frac{\partial \hat{x}}{\partial s}\left(-1+\beta \int M^{\prime} P^{\prime} d F\right)=\frac{1+x}{1+\lambda+s}\left(-1+\frac{P-(z-x)}{1+x}\right), \\
& =\frac{P-1-z}{1+\lambda+s} .
\end{aligned}
$$

Substituting this into (43) for $P_{s}$ gives

$$
\begin{aligned}
1+z+\frac{\lambda w_{s}}{(z-x)^{-\sigma}} & =P-(1+s) \frac{P-1-z}{1+\lambda+s} \\
& =\frac{\lambda P}{1+\lambda+s}+(1+s) \frac{1+z}{1+\lambda+s}
\end{aligned}
$$

Rearranging,

$$
\frac{\lambda w_{s}}{(z-x)^{-\sigma}}=\frac{\lambda P-\lambda(1+z)}{1+\lambda+s}
$$

i.e.,

$$
\begin{aligned}
w_{s} & =(z-x)^{-\sigma} \frac{P-(1+z)}{1+\lambda+s} \\
& =(z-x)^{-\sigma} \frac{(1-\sigma)(z-x[s, z])^{\sigma} w(s, z)-(1+z)}{1+\lambda+s} \\
& =\frac{1}{1+\lambda+s}\left([1-\sigma] w-(1+z)[z-x]^{-\sigma}\right)
\end{aligned}
$$

But this is the same as (14).

Lemmas 7 and 8 then imply the main result of this section:

Proposition 4 The incomplete-market economy has an efficient equilibrium.

For general parameter values, we cannot rule out other equilibria that are not efficient. 


\subsubsection{The effects of financial-market completion}

If the efficient equilibrium were in fact unique, we could conclude that if all firms are publicly traded, the emergence of a seeds market should affect neither prices nor quantities. It is enough that all firms trade on the stock market. Even in a financially developed society like the U.S., however, only about one half of the privately owned capital trades on stock markets, and therefore further enlargement of the stock market would probably raise efficiency, as Greenwood and Jovanovic (1990) found in a model in which different-sized firms gradually join the stock market as they grow.

The efficiency result should extend to a situation in which firms do differ because, e.g., they draw different z's. Jovanovic and Braguinsky (2004) develop a related one-period model in which firms differ in two dimensions: Project quality which we can interpret as $s$, and managerial ability, which we can interpret as $z$. They find that even when $s$ is private information to the firm being acquired, the stock market achieves efficiency.

As far as translating these results to the market for information generally, we must qualify all this by noting that seeds, $S$, do not share some of the features of inventions that are sometimes thought important. Namely,

1. Seeds are of purely private value, and not costlessly reproducible - as information perhaps is - and cannot raise output in more than one firm;

2. The producer of a seed has a perfect property right to it even when markets for seeds do not exist.

If either assumption did not hold, equilibrium would not be efficient. Moreover, if inventions were embodied in people and if people could extract the rents from the firm, then Q would certainly be different and equilibrium could be inefficient.

\section{$5 \quad$ Numerical solution and fitting the data}

The Appendix provides more details on the data and procedure.

Process for $z$.- I shall restrict the realizations of $z$ to just five values. Since $z$ is estimated as $Y / k$, its value is sensitive to how capital operated by private firms is classified. It is likely that a lot or the wartime capital was mis-classified as Government capital when in fact it was used by the private sector (Gordon 1969). Accordingly the empirics will start in 1953. But we shall then also take out a constant and linear trend from $z$, on the presumption that we do not measure the true $k$. In this way we get a trendless $z$, which is what the model assumes. When detrended linearly, $z$ follows an AR(1) process with autocorrelation coefficient 0.93, and innovation standard deviation 0.03. The Tauchen-Hussey procedure for discretizing the AR yields a first-order Markov chain with 5 evenly spread-out states, 
$\left(z_{1}, z_{2}, z_{3}, z_{4}, z_{5}\right)=(0.32,0.34,0.36,0.38,0.40)$, and the symmetric transition probability matrix in Table A:

\begin{tabular}{c|ccccc|c} 
& $z_{1}$ & $z_{2}$ & $z_{3}$ & $z_{4}$ & $z_{5}$ & Stationary dist. \\
\hline$z_{1}$ & 0.71 & 0.27 & 0.02 & 0.00 & 0.00 & 0.15 \\
$z_{2}$ & 0.18 & 0.55 & 0.24 & 0.02 & 0.00 & 0.22 \\
$z_{3}$ & 0.01 & 0.22 & 0.53 & 0.22 & 0.01 & 0.25 \\
$z_{4}$ & 0.00 & 0.02 & 0.24 & 0.55 & 0.18 & 0.22 \\
$z_{5}$ & 0.00 & 0.00 & 0.02 & 0.27 & 0.71 & 0.15
\end{tabular}

Table A: The Matrix of transition probabilities For $z$

which induces the autocorrelation coefficient of 0.93 and standard deviation of 0.03 - the same as the data.

Parameters. - At this point we assume that $k$ depreciates at the rate $\delta$ and $S$ depreciate physically ${ }^{9}$ at the rate $\gamma$ so that their laws of motion (2) and (4) become $k^{\prime}=(1-\delta) k+X$ and $S^{\prime}=(1-\gamma)(S+\lambda k-X)$ respectively. The parameter values used are shown in Table B:

\begin{tabular}{|c|c|c|c|c|c|c|}
\hline$\beta$ & $\sigma$ & $\delta$ & $\bar{z}$ & $s_{0}$ & $\lambda$ & $\gamma$ \\
\hline 0.95 & 6.23 & 0.043 & 0.36 & 0.03 & 0.075 & 0.11 \\
\hline
\end{tabular}

Table B: Parameter values for the Seeds model

\subsection{Simulated decision rules and $Q$.}

For the parameter values and transition probabilities stated in the above tables, Figure 4 plots the equilibrium $Q$, the decision rules and the value function. In all the plots, the variable on the horizontal axis is $s$, the beginning-of-period seeds-capital ratio. For the sake of clarity we shall omit the decision rules corresponding to $z_{2}$ and $z_{4}$. We may summarize the plots as follows:

1. Panel (a) of Figure 4 plots Tobin's $Q .{ }^{10}$ As $s$ gets large, $p(s, z) \rightarrow 0$ for all

\footnotetext{
${ }^{9}$ Of course $\gamma$ tries to capture what in fact is obsolescence, and not physical depreciation. If the model is to fit at the national level, then we should use a number for obsolescence of U.S. knowledge because of being superseded by firms other nations. Presumably it is smaller than the rate at which the patents of a firm obsolesce. One typically uses 15 percent for domestic obsolescence, and some combinantion of this number with the fraction of patenting abroad and the fraction that foreigners patent in the U.S. would be needed to come up with the right number for $\gamma$. See Eaton and Kortum (1999) for some of the relevant numbers.
}

${ }^{10}$ To calculate $Q$ we substitute fom (14) into (30) to obtain

$$
\begin{aligned}
p(s, z) & =(z-x)^{\sigma} \frac{1}{1+\lambda+s}\left([1-\sigma] w-(1+z)[z-x]^{-\sigma}\right) \\
& =\frac{1}{1+\lambda+s}\left(\frac{1-\sigma}{(z-x)^{-\sigma}} w-[1+z]\right)
\end{aligned}
$$


a) Tobin's $Q, Q(s \mid z)$
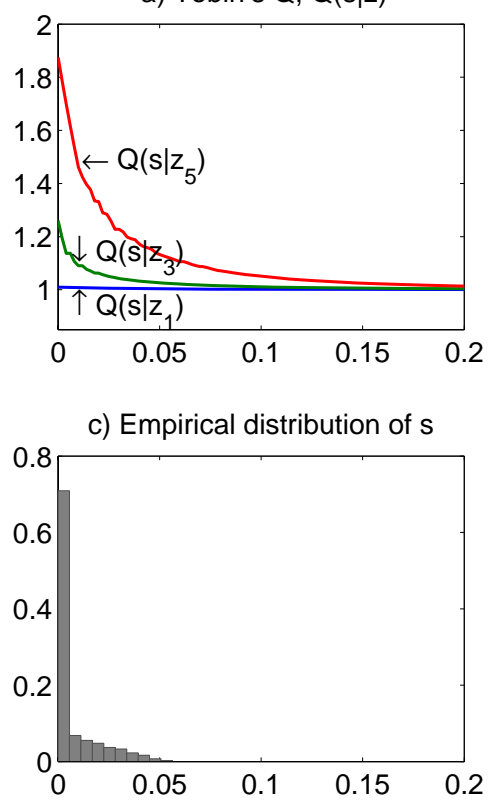

b) Investment, $x(s \mid z)$

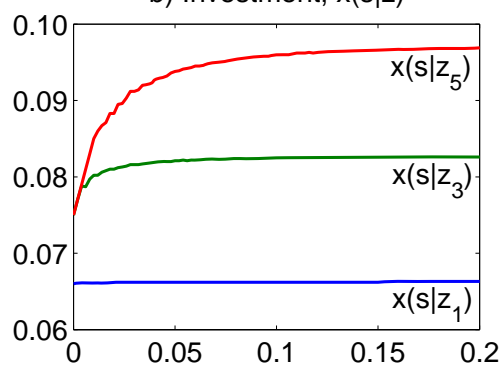

d) Scaled value function, $w(s \mid z)$

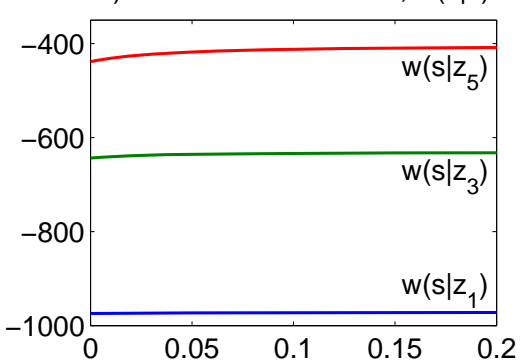

Figure 4: DeCISION RUles AND EQUILIBRIUM PRICES

$z$, and therefore $Q(s, z) \rightarrow 1$. The maximal $Q$ of 1.87 occurs when $s=0$ and $z=z_{5}$.

2. Panel (b) plots investment, which responds more to $s$ when $z$ is high. At $z_{3}, z_{4}$, and $z_{5}$, investment is constrained at low values of $s$. E.g., $x\left(s, z_{5}\right)=\lambda+s$ when $s$ is close to zero, so that the initial slope of the red curve in Panel (b) is unity. When $z \in\left\{z_{1}, z_{2}\right\}$, however, $x$ is never constrained and $s$ then has a much smaller effect on it. Referring again to Figure 3 , neither $z_{1}$ nor $z_{2}$ lies in $\Delta$ for any value of $s$.

3. Panel (c) of Fig. 4 plots the long-run distribution of seeds. Seventy percent of the time seeds are in the $s=0$ bin, but this bin also contains some positive but small values of $s$, and in fact $s=0$ occurs only 55 percent of the time. The maximal value is 0.056 .

4. Finally, the last panel plots $w$ which is negative (because $\sigma>1$ ) and increasing in both $s$ and $z$.

We actually use a version that allows positive $\delta$ and $\gamma$. Finally, (21) gives us $q$, which is the market value of planted trees in the complete-market decentralization, and the value of the firm in the incomplete-market decentralization. 
The effect of $s$ is to move $x$ and $Q$ in opposite directions. On the other hand, $z$ moves $x$ and $Q$ in the same direction, and this effect dominates so that the correlation between $x$ and $Q$ is positive as the matrix of unconditional correlations for the data and model in Table $\mathrm{C}$ shows:

\begin{tabular}{cccc} 
& $s$ & $x$ & $Q$ \\
\hline$z$ & -0.04 & 0.49 & 0.71 \\
$s$ & & -0.11 & $\mathbf{- 0 . 1 9}$ \\
$x$ & & & 0.33
\end{tabular}

Data

\begin{tabular}{cccc} 
& $s$ & $x$ & $Q$ \\
\hline$z$ & -0.58 & 0.45 & 0.94 \\
$s$ & & -0.08 & $\mathbf{- 0 . 6 0}$ \\
$x$ & & & 0.14
\end{tabular}

Model

Table $C$ : The Matrix of UnConditional CORRelations in the DATA AND IN THE MODEL

The signs the model produces are correct, but the magnitudes are far apart in some cases, most notably the correlation between $s$ and $z$. The model generates the strong positive correlation between $z$ and $Q$ and the negative correlation between $s$ and $x$. The largest discrepancy is the relation between $s$ and $z$.

\section{2 $\quad$ Fitting the post-war series}

The state variables of the model are $k, S$, and $z$, and the decision variable is $x$. In addition, we focused on the price of seeds, $p$, but the real motivation for it is the role that $p$ plays in the price of the firm, $Q$. Thus we shall fit the following postwar series: ( $i$ ) The output-capital ratio, $z$, (ii) The seed-capital ratio, s, (iii) The investment-capital ratio, $x$, and (iv) Tobin's $q$ as given in (31).

In all four Panels of Figure 5, the dashed (red) lines represent the model, the solid (blue) lines represent the data. Most of the parameters were chosen to minimize the RSS between the simulated and constructed series. The variables were constructed as follows:

1. The dashed line in Panel (a) of Figure 5 plots $z=Y / k$. The model has 5 values of $z$ to fit this with.

2. Panel (b) plots the series for $s$ implied by the model as the dashed line, calculated via

$$
s^{\prime}=(1-\gamma) \frac{\lambda+s-x}{1-\delta+x},
$$

where $s_{0}=0.03$. The solid line is our estimate of the seeds series, using patent applications as explained in the Appendix. Constructing the estimated series involved the introduction of a parameter $\theta=0.04$ for converting units of seeds into units of $k$ The simulated $s$ peaks at 0.42 in the late $80 \mathrm{~s}$. The model overpredicts the empirical estimate of $s_{t}$, i.e., the estimate of the seeds series that produces the model's best fit to the post-war data. Instead of using patent applications, we experimented with new trademarks and with R\&D and as proxies for $\lambda k$, but the model's fit of the $s$ series did not improve. 
a) Simulated productivity shock

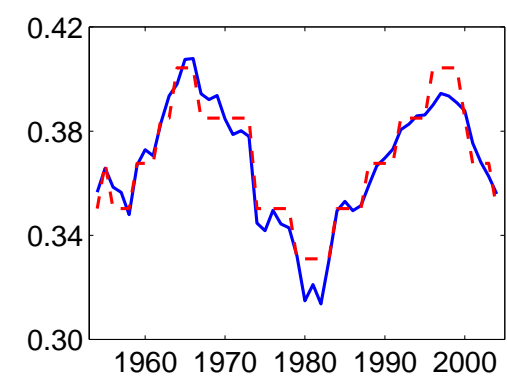

c) Simulated investment, $x(s, z)$

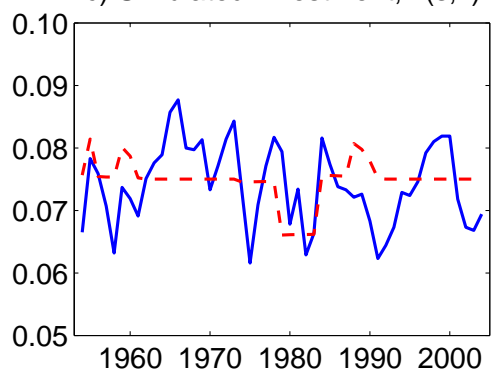

b) Simulated s'(s,z) series, $s_{0}=0.03$

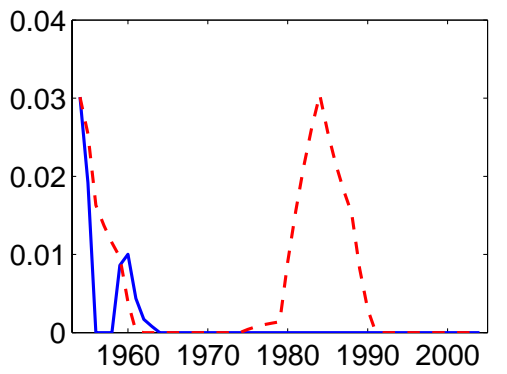

d) Simulated Tobin's Q, Q(s,z)

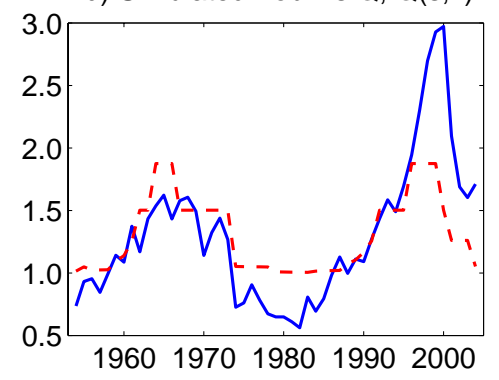

Figure 5: Time PATh of The DATA AND MOdEL OUtComes

3. Panel (c) shows that the model does not solve the excess-volatility puzzle, but we'll see that it does better than the ACM on this score. The influence of $z$ on $Q$ is more important than that of $s$.

4. In Panel (d) of Figure 5 we plot the actual and fitted $Q$. For the measured $Q$, for 1951-1999 we use Hall's series, but since it ends in 1999, for the period 1999-2004 we use Abel's data scaled so that the two Q series match in 1999. This is the dashed line in Panel (d) of Figure 5. To get a sustained rise in $Q$ we must have a prolonged period during which $z=z_{5}$. The ' 90 s appear to have been such a period. Evidently, the seeds model explains more of the variation in $Q$, but it overpredicts the volatility of $x$ by more. Of course, this model cannot ever generate $Q<1^{11}$

As an explanation for the behavior of $Q$ in panel (d), the model has a problem with reconciling $Q$ with the following properties of the time-series for $z$ :

\footnotetext{
${ }^{11}$ Since investment is in fact always positive, the constraint $X \geq 0$ (if we were to impose it) would never be violated. A second way to explain why $Q$ is sometimes below 1 is to introduce more than one type of capital. But when there are several types of capital, the arrival of a better new capital will cause the value of old capital to fall. Greenwood and Jovanovic (1999) and Hobijn and Jovanovic (2001) argue that this this explains the low Q in the 1974-86 period, and Jovanovic and Rousseau (2007) study the entire Twentieth Century using similar logic.
} 
- $Y / k$ falls dramatically in the late '70s and early ' 80 s, something that the model interprets as a low- $z$ epoch causing the huge buildup of seeds portrayed in panel (b) and the resulting collapse of $Q$ to its lowest possible level of unity, and

- The long productivity slowdown of the 70's and early '80s delays the predicted rise in $Q$ to the '90s. In fact, $Q$ starts its rise in the early ' 80 s. Even with the accompanying rise in the estimate of $z$, it takes time for the model $s$ (the solid line) to be drawn to zero and for $Q$ to rise to its maximal value of 1.88 .

\section{Intangibles and $Q$}

The market value of $k$ is $1+p$ and the market value of $s$ is $p s$. Since $p$ is decreasing in $s$, marginal $q$ is decreasing in $s$. But we have to show that measured $Q$, which is given in (31), is decreasing in $s$. The next Proposition derives a sufficient condition for that to be so.

Proposition $5 Q^{a}$ is monotone decreasing in $s$ for all $s \geq 0$ if

$$
\sigma \geq 1+\lambda
$$

Proof. The proof will assume that $x$, and hence $Q^{a}$, are everywhere differentiable in $s$ (if it is not differentiable the conclusion that $Q^{a}$ declines remains the same). Then

$$
\frac{\partial Q^{a}}{\partial s}=p+(1+s) p_{s}
$$

On the set $\Delta, x=\lambda+s$ so that $\frac{\partial x}{\partial s}=1$. Off the set $\Delta, \frac{\partial x}{\partial s}<1$. Using (14), and $p=\frac{1}{1+\lambda+s}\left([1-\sigma] w[z-x]^{\sigma}-(1+z)\right)$.

$$
\begin{aligned}
p_{s} & =\frac{1}{1+\lambda+s}\left(-p+[1-\sigma]\left(\sigma w[z-x]^{\sigma-1} \frac{\partial x}{\partial s}+w_{s}[z-x]^{\sigma}\right)\right) \\
& \left.\leq \frac{1}{1+\lambda+s}(-p+[1-\sigma] p) \quad \text { (because } \frac{\partial x}{\partial s} \geq 0\right) \\
& =-\frac{1}{1+\lambda+s} \sigma p
\end{aligned}
$$

therefore

$$
\frac{\partial Q^{a}}{\partial s}=p-\frac{1+s}{1+\lambda+s} \sigma p \leq\left(1-\frac{\sigma}{1+\lambda}\right) p,
$$

from which (46) follows.

The proposition offers only a sufficient condition, but it also can be shown that for $\sigma$ sufficiently small, $Q^{a}$ rises with $s$. Nevertheless, condition (46) holds at realistic values of $\sigma$ and $\lambda$ that in the simulation are 2 and 0.135 respectively. This is why the 
seeds model implies a fall in $Q$ whereas Hall's (2000) implies a rise in $Q$. In my model, variation in intangibles is caused by variation in the stock of unimplemented seeds. In Hall's model there are variable proportions between intangibles and physical capital in production and there is no storage of intangibles, hence a rise in intangibles gives a rise in the productivity of the firm's measured capital and (barring the GE effects that I have emphasized here) it produces a rise in the firm's $Q$.

In the two panels of Table 3 we have already seen that the correlation between $s$ and $Q$ (the bolded numbers in the two panels) is negative. The finding is robust to extending the number of $z$ 's to five - see Table A3. Let us explain this finding in more detail. In the model the stock $S$ denotes unexercised options. Thus a rise in $s$ represents a rise in the ratio of unimplemented intangible capital to tangible capital. The stock of all intangible capital is $k+S$ with $k$ being the number of seeds already in the ground and being used for production. Therefore the ratio

$$
\frac{\text { All intangible capital }}{\text { Tangible capital }}=\frac{k+S}{k}=1+s
$$

is also monotone in $s$. Therefore, $s$ is also an index of all options, be they implemented or not.

Evidence.-Whether intangibles raise $Q$ or lower thus ultimately depends on whether intangibles enter final goods production independently of $k$ as Hall assumes, or whether they are embodied in $k$ as I have assumed here. One source of evidence is the aftermaths of large wars during which industry resources tend to mobilize for aiding the war effort and during which unexercised options are likely to accumulate. In other words, prolongued wars lead to a buildup of seeds as a result of wartime research for military purposes. This means that after the war there should be a stock of unimplemented ideas and $Q$ should be low. The evidence from the U.S. and the U.K. shows that $Q$ was exceedingly low after both world wars. Figure 6 reproduces Figure 5 from Wright (2004). It shows that of the three epochs when Q was at its lowest, the first was following WW1 and the second was following WW2. The same is true for U.K. $q$ as Figure 7 (a reproduction of Chart 8 of Smithers 2007) shows. Since the price of capital goods has been declining faster than that of consumption goods, we may expect that ideas predominate in the production function for $k$, and not the production function for final goods.

Several alternative explanations come to mind that may explain low post-war Qs. First, one may wonder whether there is some purely accounting reason why the denominator of $\mathrm{Q}$ was somehow artificially inflated after WW2, having to do with whether capital was mis-classified so that the denominator of $Q$ was perhaps too high But exactly the opposite seems to have been the case - Gordon (1969) convincingly establishes that much Government capital was, for several years after 1945, operated for profit by private firms, yet not counted as private capital, and excluded from the book values of those firms. Gordon argues further that this accounting practice this 


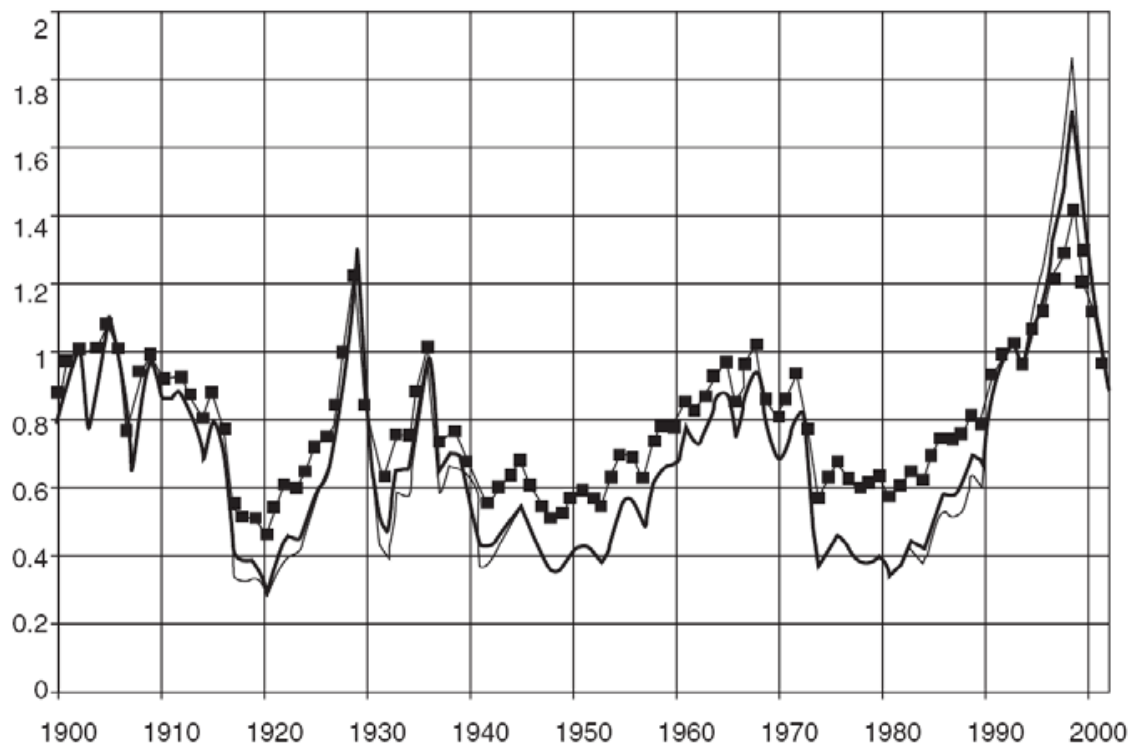

Figure 6: three series for Tobin's Q from Figure 5 of Wright (2004).

raised the measured rate of return on Corporate assets. On these grounds, then, we would have expected post-war Q to have been high, not low.

A second explanation for low Q after WW2 is that the market expected a severe postwar recession that would take profits and employment after 1945 down to something like the late 1930s, that this fear was not fully dispelled until the mid 1950s, and that only then did markets become convinced that the economy was capable of peacetime prosperity. This argument will not explain why Q was low after WW1, however, and the hypothesis still awaits a systematic test.

A third possibility is that after the war there was a consumption boom with people wanting to borrow and thereby bidding up the interest rate and the rate at which earnings are discounted, and thereby lowering Q. But interest rates after the war were near all time lows. Figure 29 of Jovanovic and Rousseau (2006) shows that the ex-post real interest rate on 60- and 90-day commercial paper was negative for most of the late 1940s.

Corrado, Hulten and Sichel (2005) and Hall (forthcoming) estimate that the stocks of intangibles rose during the 90 's. The seeds model is consistent with this fact only if we assume that what these authors measure is exercised options. Bronwyn Hall's production function estimates can be reconciled with the seeds model if we assumed that the quality of $k$ is not properly measured, and that the measurement error depends on the number of seeds embodied in the capital. One would need to relax the Leontieff assumption of one seed to one tree, and introduce variable proportions. 


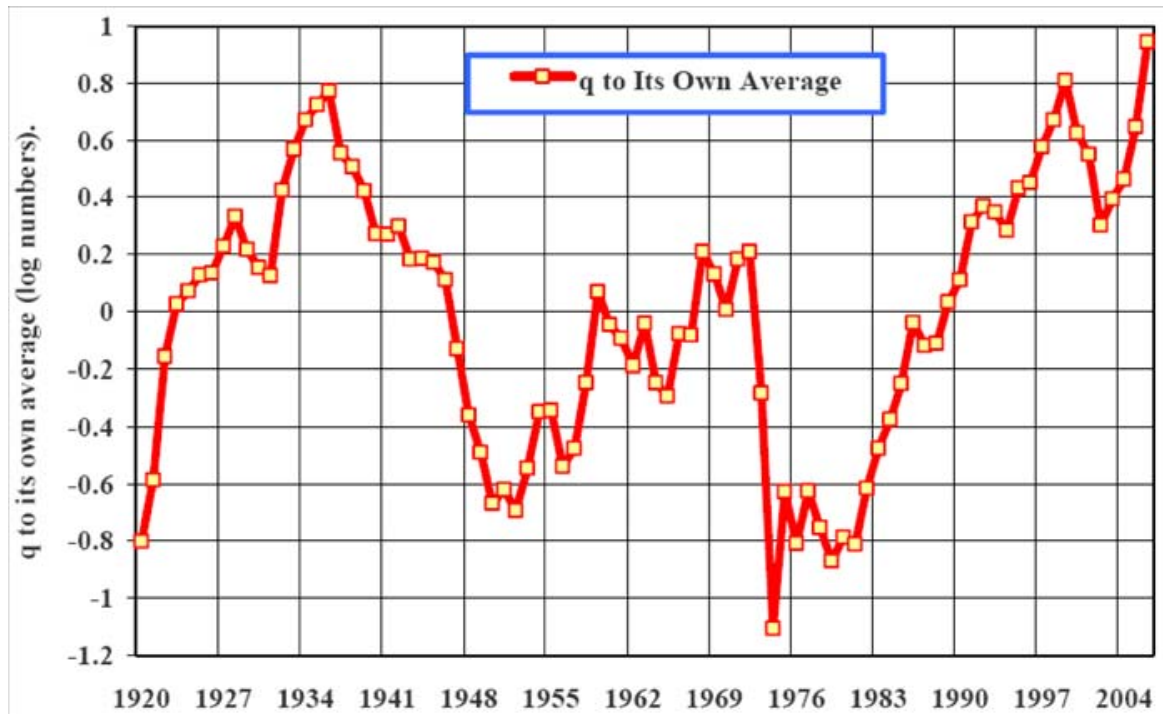

Figure 7: ToBIN's Q IN THE U.K., 1920-2006

\section{Comparison to the adjustment-cost model (ACM)}

The ACM is specified in (10). As we saw in the beginning of Section 2, the difference between the Seeds model and the ACM is in the nature of the adjustment cost. Since $s_{t}=s_{0}+\sum_{j=0}^{t-1}(1-\gamma)^{j}\left(\lambda-x_{t-j}\right)$, substituting for $s$ in (9) yields an investment cost of the form $\hat{C}\left(x_{t}, x_{t-1}, x_{t-2}, \ldots\right)$, which is increasing in all its arguments. For any $j>0$, a rise in $x_{t-j}$ tightens the constraint at $t$. We use the same $(\beta, \sigma, \delta)$ and the same process for $z$ as for the Seeds model. We then choose $\left(\lambda^{*}, \phi\right)$ to fit the first moments of $x$ and $Q$. The Appendix supplies more detail. The procedure gives us the estimates in Table D:

\begin{tabular}{|c|c|}
\hline$\lambda^{*}$ & $\phi$ \\
\hline 0.6 & 1.8 \\
\hline
\end{tabular}

Table D: Values of the NeW Parameters of the ACM

In the $\mathrm{ACM}, z$ is the only state variable and therefore a one-to-one relation emerges between $x$ and $Q$, namely the FOC

$$
Q=1+h^{\prime}(x)=1+\left(\lambda^{*}\right)^{-\phi} x^{\phi-1},
$$

which, since $\phi$ is close to 2 is almost linear and is plotted in Figure (8).

In Figure (8) we indicate on the horizontal axis the value of the Seed-model parameter $\lambda=0.075$. The Seeds model has just one shock, $z$, the same as in the 


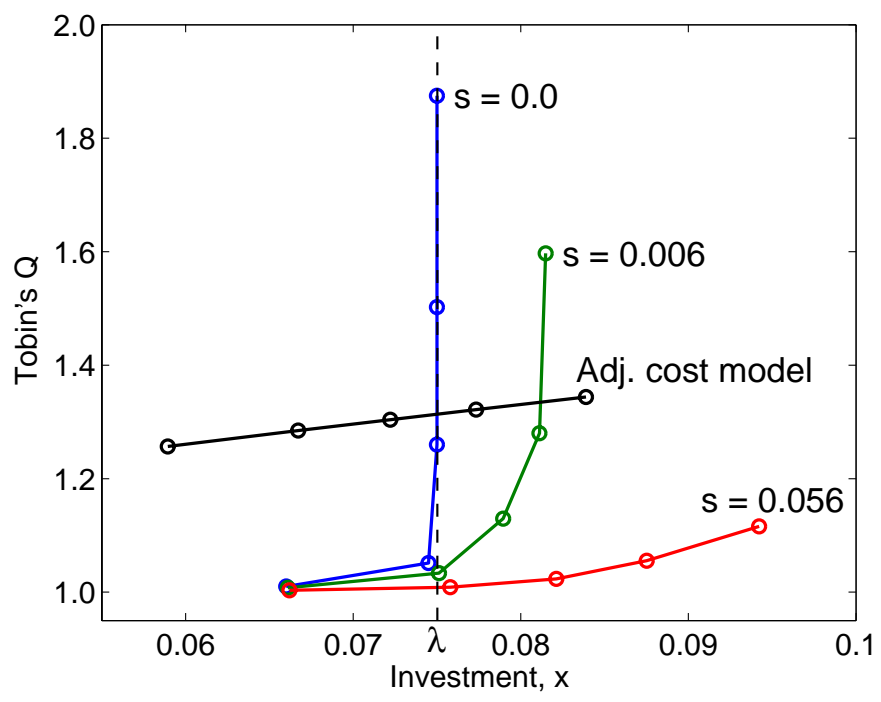

Figure 8: Investment and $Q$ In the Seeds and Adjustment-Cost Models

ACM, but it has a second state variable, $s$, on which $x$ and $Q$ both depend, and this loosens the relation between $x$ and $Q$. Thus Abel and Eberly's (2006) argument carries over to the aggregate setting. Panel (c) of Fig. 4 shows that in the long run the steep red curve (pertaining to $s=0$ ) and similar curves for $s$ vales close to zero are relevant seventy percent of the time. This curve becomes vertical at $x=\lambda=0.075$. The next line pertains to the median value $s=0.006$, and it becomes vertical at $x=0.075+0.006=0.081$. The most elastic curve becomes vertical at 0.131 , not shown in the figure.

Next, let us contrast the two models' implications for the second moments of the data when both are constrained to fit the first moments. This is done in Table E. Column 2 reports the moments of the data. Columns 3-6 report the results of three 100,000-period simulations of two models when the shocks are drawn according to the transition matrix in (44). Columns 3-5 of Table E report the statistics for three versions of the Seeds model.

Column 3 presents the Seeds model under the parameter values that, together with (44), were used to generate Figure 4 and Figure 5. The initial condition is $s_{0}=0.04$. One should compare the numbers in Column 3 to the information in Figure 4. For instance, $E(s)$ and $\sigma(s)$ are the mean and standard deviation of the distribution of $s$ plotted in Panel (c) of Figure 4. For the ACM we choose $\phi$ and $\lambda^{*}$ to fit $E(x)$ and $E(Q)$, which the Seeds model also fits. Otherwise, all the parameters that the two models have in common are the same for the two models.

The Seeds model vs. the ACM.-The ACM explains the volatility of $x$ better; the Seeds model underpredicts $\sigma(x)$. On the other hand, the Seeds model does a lot better with $\sigma(Q)$ while still falling short by a factor of almost two. but it 
underpredicts $\sigma(Q)$ and $\sigma(c)$ by less. Finally, the Seeds model has an additional endogenous variable - seeds - and no new exogenous variables, but as we have seen in Figure 5 it does not explain well any reasonable measure of seeds. Consumption volatility is the same in the two models, but investment is more volatile in the ACM. Nevertheless, the Seeds model explains much better the volatility of $Q$, as Figure 8 suggested.

How much does intertemporal substitution matter?-At the outset of Section 2 we argued that the substantive difference between the Seeds model and the ACM is in that the former has intertemporal substitution in investment. Column 4 shuts off the ability to store seeds but otherwise keeps the same parameters as underlie Column 3. ${ }^{12}$ As expected, the volatility of investment falls and that of consumption rises but, surprisingly, the volatility of $Q$ does not rise. How general this conclusion is remains to be investigated.

\begin{tabular}{cccccc} 
Moment & Data & SDM & SDM $(\gamma=1)$ & SDM $\left(s_{0}=\infty\right)$ & ACM \\
\hline$E(z)$ & 0.37 & 0.367 & 0.367 & 0.368 & 0.368 \\
$E(x)$ & 0.07 & 0.074 & 0.074 & 0.082 & 0.073 \\
$E(s)$ & 0.002 & 0.007 & 0.000 & - & - \\
$E(Q)$ & 1.30 & 1.303 & 1.316 & 1.000 & 1.301 \\
$E(c)$ & 0.30 & 0.293 & 0.294 & 0.285 & 0.290 \\
$\sigma(z)$ & 0.027 & 0.024 & 0.024 & 0.023 & 0.023 \\
$\sigma(x)$ & 0.007 & 0.004 & 0.003 & 0.010 & 0.073 \\
$\sigma(s)$ & 0.009 & 0.012 & 0.000 & - & - \\
$\sigma(Q)$ & 0.566 & 0.302 & 0.299 & 0.000 & 0.069 \\
$\sigma(c)$ & 0.020 & 0.021 & 0.022 & 0.014 & 1.000 \\
\hline \multicolumn{5}{c}{ Table $E:$ THE SEEDS MODEL AND THE ACM }
\end{tabular}

The effect of dropping the seed constraint.-Column 5 drops the seeds constraint by endowing the economy with an infinite supply of seeds at the outset. Here things work as expected. This becomes the standard growth model without adjustment costs. Then $Q$ is always unity, and $\sigma(x)$ rises above the level reached even by the ACM.

Cash-flow regressions. - It is customary to regress investment on $Q$ and on cash flow and when cash flow "drives $Q$ out" of the regression, this is held to be a problem for $Q$ theory. But, as Abel and Eberly (2005) stress, investment options are not always exercised, but their value changes over time, and with it the firm's measured $Q$, and therefore the significance of cash flow independently of $Q$ does not indicate a failure of the $Q$ theory. While they have established that convincingly for the cross section, it remains to be seen whether the same conclusion holds in the time series in the GE

\footnotetext{
${ }^{12}$ At this point, the ACM is more flexibly parametrized than the Seeds model because, as we noted in Proposition 1, the case where seeds cannot be stored is in fact a special case of the ACM
} 


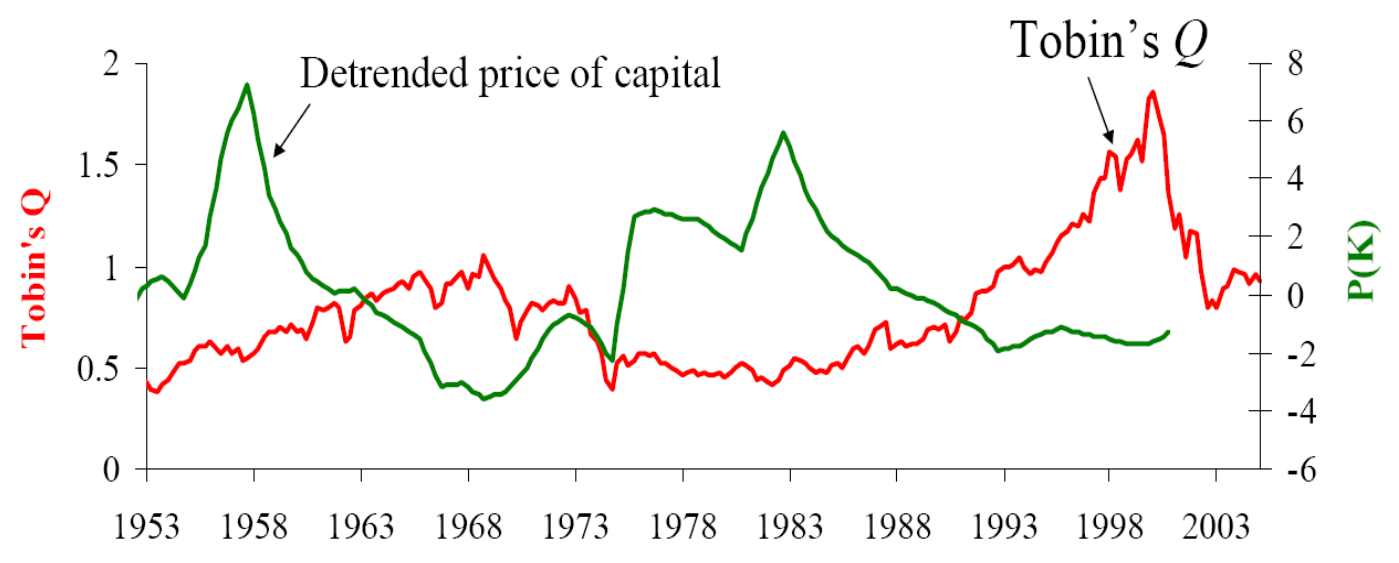

Figure 9: Tobin's $Q$ And the Relative PRICE of CAPital 1953-2001

context. Per unit of $k$, net cash flow is the same as aggregate consumption, $z-x$. We shall therefore simulate the results of such a regression by taking a million draws of the model and subjecting the endogenous variables to the regression in question. The results were

$$
\underset{\text { INVESTMENT }}{x_{t+1}}=-0.02+0.44\left(z_{t}-x_{t}\right)-0.03 \underset{\text { MASH }}{Q_{t}^{a}} Q_{\text {MEASURED Q }}^{a} .
$$

where $Q^{a}$ was simulated via (31), i.e., from the first decentralization. Given the large sample size, all three coefficients differ significantly from zero. The reason why cash is positive seems to be that $z-x$ increases in $z$, and $z$ is persistent, leading on average to a higher $x^{\prime}$.

\section{Other information about $\left(p_{t}\right)$}

One could summarize this paper by saying that it "tries to explain $\left(Q_{t}\right)$ by generating $\left(p_{t}\right)$." So far we have not used any information on $\left(p_{t}\right)$. In this section we shall informally consider two sources of information on $p$ : $(i)$ the relative price of capital and of high skills, and (ii) the relation between a firm's Q and proxies for its $S$.

\subsection{The relative price of capital and the skill premium}

Do seeds help create cheaper machines? - Suppose that firms sell planted trees to competitive fruit companies who then sell fruit to customers. If we consider a planted tree a finished capital good, then marginal $Q$, i.e., $1+p$, should then coincide with the price of capital. This does not fit the facts, however, as Figure 9 shows; the de-trended relative price of capital is negatively related to $\mathrm{Q}$. This means that seeds 


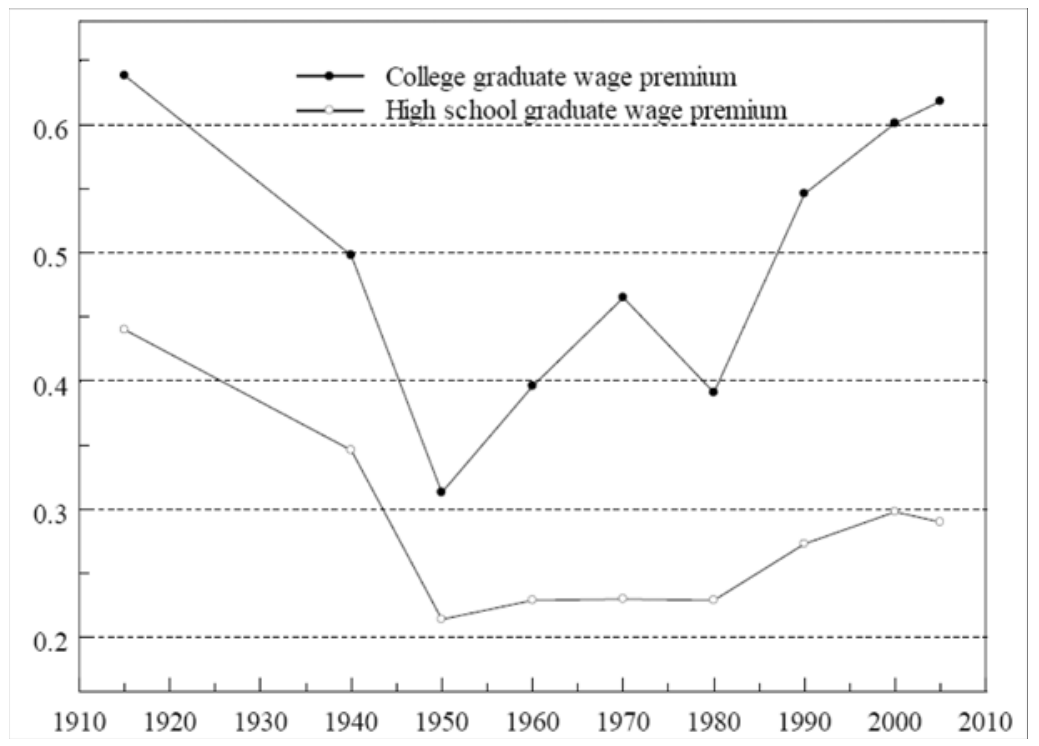

Figure 10: The Skill Premium taken from Goldin and Katz (2007)

are probably not embodied in equipment or, if they are, they do not lead to cheaper equipment.

Do seeds help create better human capital?-Perhaps it is more appropriate to think of seeds as generating human capital that is embodied in people. In that case, a lot of seeds on hand is like having a glut of technical or other advanced skills. Thinking this way leads to using the skill premium as a measure of the scarcity of skills. Since $Q$ is also high when skills are scarce, this means that $Q$ and the skill premium should be positively correlated over time. Goldin and Katz (2007) report the time series for college premium and the high-school premium. The college premium is highly correlated with $Q$ since WW2; it rises in the 50s and 60s, falls in the 70's and again starts to rise in the 80 s about the same time as does $Q$. The high-school premium is less strongly but still positively related to $Q$.

The empirics of the previous section notwithstanding, it seems more appropriate to view seeds as being embodied in human capital rather than physical capital.

\subsection{The cross-section relation between $\mathbf{Q}$ and $S$}

The cross section implications contrast with those of the time series: In periods in which the economy has many unexercised options, Q should be low, but at any date, firms with more options should have Qs that are high relative to Qs of firms that do not own any unexercised options. We can benefit from this implication and arrive at an independent estimate of the aggregate time series of $p$ and $q$.

Let us now look further into this question. So far, firms were assumed to be 


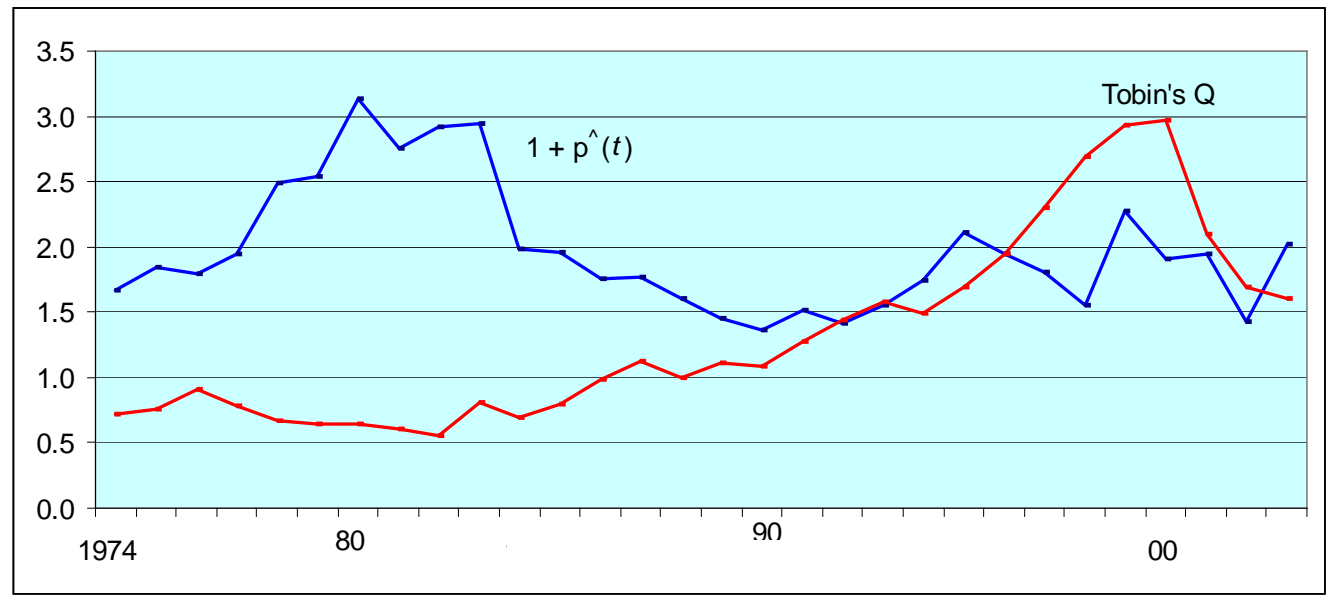

Figure 11: Estimate of $1+p\left(s_{t}, z_{t}\right)$ FROM CROSS-SECTION DATA - RESUlTS SUPPLIED BY BRONWYN HALL, 1974-2003.

identical. One can, however, inject a zero measure of firms being endowed with different relative seed stocks, $s_{i}$ but the same $z$ as all other firms. This would leave all other firms' valuations and policies unchanged.

A firm's beginning-of-period value would now depend on its state $\left(S_{i}, k_{i}\right)$, in addition to the aggregate state $(s, z)$. The aggregate $k$ would not affect the firm's price because it affects neither $q$ nor $p$. Then its beginning-of-period value per unit of capital would be

$$
\tilde{Q}_{i} \equiv \frac{1}{k_{i}} \pi\left(k_{i}, S_{i}, s, z\right)=1+z+p(s, z)\left(1+\lambda+\frac{S_{i}}{k_{i}}\right) .
$$

Since $p$ changes with the aggregate state $\left(s_{t}, z_{t}\right)$ but not with $i$, it can, for each $t$, be estimated from the cross-section regression of $Q_{i}$ on $\frac{S_{i}}{k_{i}}$, provided the latter could be reliably estimated. I report some results related to Hall (forthcoming) in Figure 11. According to the model, the two lines should have coincided, but they do not. Why don't they? Probably, it is because firms' $z$ s also differ and that firm $i$, say, has accumulated an above-average stock of seeds, $s_{i}$, precisely because its $z_{i}$ has been low. Therefore, instead of (48), we should write

$$
\tilde{Q}_{i} \equiv \frac{1}{k_{i}} \pi\left(k_{i}, S_{i}, z_{i}, s, z\right)=1+z_{i}+p(s, z)\left(1+\lambda+\frac{S_{i}}{k_{i}}\right) .
$$

Now the unobservable $z_{i}$ is negatively correlated with $S_{i} / k_{i}$, and this invalidates the interpretation we have given to Figure 11 because a rise in $Q_{i}$ would now possibly signal a lower $S_{i} / k_{i}$. 


\section{Conclusion}

This paper has offered a microfoundation for adjustment costs that emphasizes the role of new ideas in investment and in the business cycle, and that features an intertemporal substitution element missing in existing formulations of adjustment costs. This is why the model can explain the sustained rise in $Q$ during a boom such as sometimes occurs in fact. The paper has found that investment options raise the volatility of $Q$ compared to the standard adjustment-cost model. Moreover, because they facilitate the formation of new capital, new ideas reduce the value of old capital, an implication that we found was borne out in fact. Thus what we often call intangible capital acts to reduce the market value of tangible capital. Finally, we found that a stock market alone may suffice to ensure efficiency of the equilibrium.

\section{References}

[1] Abel, Andrew and Janice Eberly. "Investment, Valuation, and Growth Options." Wharton School, October 2005.

[2] Alvarez, Fernando and Nancy Stokey. "Dynamic Programming with Homogeneous Functions." Journal of Economic Theory 82, no. 1 (1998): 167-89.

[3] Bilbiie, Florin, Fabio Ghironi and Marc Melitz. "Endogenous Entry, Product Variety, and Business Cycles." 2006.

[4] Campbell, Jeffrey. "Entry, Exit, Embodied Technology, and Business Cycles." Review of Economic Dynamics 1, no. 2 (April 1998): 371-408.

[5] Chari, V. V. and Hugo Hopenhayn. "Vintage Human Capital, Growth, and the Diffusion of New Technology." Journal of Political Economy 99, no. 6 (December 1991): 1142-65.

[6] Chamley, Christophe and Douglas Gale. "Information Revelation and Strategic Delay in a Model of Investment." Econometrica, Vol. 62, No. 5. (Sep., 1994): 1065-85.

[7] Chatterjee, Satyajit and Esteban Rossi-Hansberg. "Spin-offs and the Market for Ideas." mimeo. 2007

[8] Deaton, Angus and Guy Laroque. "On the Behaviour of Commodity Prices." Review of Economic Studies 59, no. 1 (January 1992): 1-23.

[9] Eaton, Jonathan, and Samuel Kortum. "International Technology Diffusion: Theory and Measurement." International Economic Review 40, no. 3 (August 1999): 537-70. 
[10] Franco, April and Darren Filson. "Spin-outs: Knowledge Diffusion through Employee Mobility." Rand Journal of Economics, forthcoming.

[11] Fisher, Jonas. "The Dynamic Effects of Neutral and Investment-Specific Technical Change." FRB Chicago, April 2005.

[12] Goldin, C., and L. F. Katz "The Race between Education and Technology: The Evolution of U.S. Educational Wage Differentials, 1890 to 2005." NBER Working Paper No. 12984, March 2007.

[13] Gomes, Joao, Amir Yaron, and Lu Zhang. "Asset Prices and Business Cycles with Costly External Finance," Review of Economic Dynamics 6, no. 4 (October 2003): 767-788.

[14] Gordon, Robert J. "\$45 Billion of U.S. Private Investment Has Been Mislaid." American Economic Review 59, no. 3. (June 1969): 221-238.

[15] Greenwood, Jeremy, Zvi Hercowitz and Gregory Huffman. "Investment, Capacity Utilization, and the Real Business Cycle." American Economic Review 78, no. 3 (June 1988): 402-17.

[16] Greenwood, Jeremy, and Boyan Jovanovic. "Financial Development, Growth and the Distribution of Income." Journal of Political Economy 98, no.5(December 1990): 1076-1107.

[17] Greenwood, Jeremy and Boyan Jovanovic. "The IT Revolution and the Stock Market." American Economic Review 89, no. 2 (Papers and Proceedings) (May 1999): 1116-22.

[18] Hall, Bronwyn. "R\&D, Productivity, and Market Value." Annales de l'Economie et de la Statistique, forthcoming.

[19] Hall, Robert. "E-Capital: The Link between the Stock Market and the Labor Market in the 1990s." Brookings Papers on Economic Activity 2. (2000): 73-118.

[20] Hayashi, Fumio. "Tobin's Marginal q and Average q: A Neoclassical Interpretation." Econometrica 50, no. 1. (January 1982): 213 - 224.

[21] Henry, Olan, Nilss Olekalns and Jonathan Thong. "Do Stock Market Returns Predict Changes to Output? Evidence from a Nonlinear Panel Data Model." University of Melbourne, 2005.

[22] Hobijn, Bart and Boyan Jovanovic. "The IT Revolution and the Stock Market: Evidence." American Economic Review 91, no. 5 (December 2001): 1203-20.

[23] Jovanovic, Boyan. "Asymmetric Cycles." Review of Economic Studies 73, no. 1 (January 2006): 145-72. 
[24] Jovanovic, Boyan and Peter L. Rousseau. "General-Purpose Technologies." Handbook of Economic Growth 1B, Ch. 18 North-Holland (2006): 1181-1224.

[25] Jovanovic, Boyan and Peter L. Rousseau. "Vintage Organization Capital." September 2007.

[26] Khan, Aubhik and Julia Thomas. "Inventories and the Business Cycle: An Equilibrium Analysis of (S,s) Policies." American Economic Review 97, No. 4 (September 2007)

[27] Kortum, Samuel and Jakob Klette. "Innovating Firms and Aggregate Innovation." Journal of Political Economy 112, no. 5 (October 2004): 986-1018.

[28] Lentz, Rasmus and Dale Mortensen. "An Empirical Model of Growth Through Product Innovation." IZA DP \#1685, July 2005.

[29] Lucas, Robert and Leonard Rapping. "Real Wages, Employment, and Inflation." Journal of Political Economy 77, no. 5 (November 1969): 721-54.

[30] Lucas, Robert. "Asset Prices in an Exchange Economy." Econometrica 46, no. 6 (November 1978): 1429-45.

[31] Mehra, Raj and Edward C. Prescott. "Recursive Competitive Equilibrium: The Case of Homogenous Households." Econometrica 48 (September 1980): 1365-80.

[32] Pastor, Lubos and Pietro Veronesi. "Rational IPO Waves." Journal of Finance 60 (August 2005): $1713-1757$.

[33] Prescott, Edward C. and John Boyd. "Dynamic Coalitions: Engines of Growth." AEA Papers and Proceedings, (May 1987): 63-67.

[34] Sargent, Thomas. "Tobin's $Q$ and the Rate of Investment in General Equilibrium." Carnegie-Rochester Conference Series on Public Policy 12 (1980): 107-54.

[35] Serrano, Carlos. "The Dynamics of the Transfer and Renewal of Patents." University of Toronto, March 2006.

[36] Shleifer, Andrei. "Implementation Cycles." Journal of Political Economy 94, no. 6 (December 1986): 1163-90.

[37] Smithers, Andrew. "UK Stock Market: Value at End 2006." Report 285, Smithers \& Co. Ltd., January 2007.

[38] Wright, Steven. "Measures of Stock-Market Value and Returns for the U.S. Nonfinancial Corporate Sector, 1900-2002." Review of Income and Wealth 50, no. 4 (December 2004): 561-85. 
[39] Yorukoglu, Mehmet. "Product vs. Process Innovations and Economic Fluctuations." Carnegie-Rochester Conference Series on Public Policy 52 (June 2000): 137-163.

\section{Appendix 1: Data and estimation}

Data sources are described in table $1 .^{13}$

Table 1: Data sources

\begin{tabular}{lll}
\multicolumn{2}{l}{ Variable } & Data source \\
\hline$k$ & Capital stock & NIPA 6.1. Current-cost net stock of private fixed assets, line 1 \\
$Y$ & Output & NIPA 1.1.5. Gross domestic product, line 1 - line 20 \\
$X$ & Investment & NIPA 1.1.5. Gross domestic product, line 6 \\
$Q$ & Tobin's Q & 1950-99 from R.Hall, 1999- from A. Abel, spliced to Hall's series in 1999 \\
$N$ & Patents, Trademarks & See fn. 10 in Jovanovic and Rousseau (2006) \\
$k^{r}$ & Real capital stock & NIPA 6.2. Chain quantity indxs for net stock of prvt fxd assts, line 1 \\
\hline$z$ & Productivity & Computed as $z=Y / k$, linearly detrended \\
$x$ & Investment/capital & Computed as $x=X / k$ \\
$n$ & Patents/capital & Computed as $n=N / k^{r}$ \\
\hline
\end{tabular}

We estimate two models: The Seeds model and the Adjustment-Cost model. We start with the Seeds model.

Constructing $\hat{S}_{t}$. - This Appendix concerns the construction of the solid line the second panels of Figure 5. The law of motion for $S$ given (4). $S^{\prime}=\lambda k+(1-\gamma) S-X$, which assumes that seeds are measured in the same units as $k$. But there is no guarantee that this is so in fact, and so a new parameter $\theta$ must be introduced (either in the model or in the data) to convert units of patents into units of planted trees. We shall introduce the parameter in the construction of the empirical seeds series, $\hat{S}_{t}$. We assume that we can estimate $\lambda k$ by

$$
\hat{\lambda k}=\theta \cdot(\text { New Patents })
$$

and, to prevent $\hat{S}_{t}$ from becoming negative, we change (4) to

$$
\hat{S}^{\prime}=\max (0,(1-\gamma) \hat{S}-X+\theta \cdot(\text { New Patents })) .
$$

\footnotetext{
${ }^{13}$ For Patents we use the total number "utility" (i.e., invention) patents from the U.S. Patent and Trademark Office for 1963-2000, and from the U.S. Bureau of the Census (1975, series W-96, pp. 957-959) for 1946-62. The number of registered trademarks is from the U.S. Bureau of the Census (1975, series W-107, p. 959) for 1946-1969, and from various issues of the Statistical Abstract of the U.S. for later years.
} 
Dividing through by $k$ from the data (see table 1), and taking an initial condition equal to that in the data we obtain the estimated seeds series plotted as the solid blue line in panel 2 of Figure 5:

$$
\hat{s}^{\prime}=\max \left(0,(1-\gamma) \frac{\hat{s}-x+\theta \frac{\text { NEW PATENTS }}{\text { CAPITAL STOCK }}}{1-\delta+x}\right) .
$$

The model prediction, the dashed line in Figure 5, is generated by (7) with the initial condition, $s_{0}$, also a parameter to be estimated - and set to the same value $s_{0}$ for both the empirical and the theoretical series.

The estimation procedure is non-linear least squares. Model parameters are chosen to minimize the $L_{2}$-norm between the observed series $(s, x, Q)$ and the same series obtained from the data. The Seed model's parameters were chosen in two steps:

1. Parametrizing the $z$ process. - In the first step the estimated from the data productivity process $z$ is discretized into a 5-state first-order Markov process using Tauchen-Hussey procedure. Productivity process was estimated to be an $\operatorname{AR}(1)$ process with autoregressive coefficient $\rho=0.93$ and standard deviation $\sigma_{z}=0.03$. The mean level of $z$ was chosen to match the average $\mathrm{Y} / \mathrm{k}$ ratio in the data. Table 2 reports the Markov transition matrix of the approximating 5-state process. This one is not restricted to be symmetric.

Table 2: Approximating 5-state Markov process for productivity process

\begin{tabular}{c|ccccc|c} 
& $z_{1}$ & $z_{2}$ & $z_{3}$ & $z_{4}$ & $z_{5}$ & Stationary dist. \\
\hline$z_{1}=0.32$ & 0.71 & 0.27 & 0.02 & 0.00 & 0.00 & 0.15 \\
$z_{2}=0.34$ & 0.18 & 0.55 & 0.24 & 0.02 & 0.00 & 0.22 \\
$z_{3}=0.36$ & 0.01 & 0.22 & 0.53 & 0.22 & 0.01 & 0.25 \\
$z_{4}=0.38$ & 0.00 & 0.02 & 0.24 & 0.55 & 0.18 & 0.22 \\
$z_{5}=0.40$ & 0.00 & 0.00 & 0.02 & 0.27 & 0.71 & 0.15
\end{tabular}

Next $\hat{z}_{t}$ was chosen to minimize the distance to the observed level of $z_{t}$,

$$
\hat{z}_{t}=\arg \max _{\hat{z}_{t} \in\left\{z_{1}, . ., z_{5}\right\}}\left(\hat{z}_{t}-z_{t}\right)^{2}
$$

except for the period 1996-1999 when the $z_{t}$ was set to $z_{5}$ (the largest $z$ ) so that a better fit to $Q$ could be obtained.

2. Choosing the other parameters.-Let us choose parameters so that the model when fed with the sequence $\left\{\hat{z}_{t}\right\}$ generates series $(\hat{s}, \hat{x}, \hat{Q})$ close to those observed in the data,

$$
\min _{\lambda, \gamma, \theta, s_{0}} w_{s} \sum_{i=1}^{51}\left(\hat{s}_{i}-s_{1953+i}\right)^{2}+w_{x} \sum_{i=1}^{51}\left(\hat{x}_{i}-x_{1953+i}\right)^{2}+w_{Q} \sum_{i=1}^{51}\left(\hat{Q}_{i}-Q_{1953+i}\right)^{2}
$$


subject to

$$
E\left[\hat{x}_{i} \mid \lambda, \bar{z}, \gamma, s_{0}, \theta\right]=0.0740, \quad E\left[\hat{Q}_{i} \mid \lambda, \bar{z}, \gamma, s_{0}, \theta\right]=1.3025
$$

The weights $\left(w_{s}, w_{x}, w_{Q}\right)$ are set to values $(2,2,0.01)$.

The seeds model parameters are reported in table 3 . Parameter $\beta$ was set to match the annual risk free rate of $5 \%$. Parameter $\delta$ was set to equal the average of the values given by the RHS of the following rearrangement of the law of motion for $k$ : $\delta=\frac{X_{t}}{k_{t}}+1-\frac{k_{t+1}}{k_{t}}$. Parameters $\sigma, \lambda, \theta, s_{0}$ were chosen by the optimization routine (51).

Table 3: Parameters Values for The Seeds Model

\begin{tabular}{|c|c|c|c|c|c|c|c|c|}
\hline$\beta$ & $\sigma$ & $\delta$ & $\bar{z}$ & $s_{0}$ & $\lambda$ & $\gamma$ & $\theta$ & \\
\hline 0.95 & 6.23 & 0.043 & 0.36 & 0.03 & 0.075 & 0.11 & 0.04 & \\
\hline
\end{tabular}

The adjustment-cost model.-ACM's cost function is specified in (10) as

$$
h(x)=\frac{1}{\phi}\left(\frac{x}{\lambda^{*}}\right)^{\phi} .
$$

Parameters $\beta, \sigma, \delta$ are fixed at the values used for the Seeds model. The parameters $\left(\phi, \lambda^{*}\right)$ are chosen to minimize

$$
\left(E\left(x \mid \phi, \lambda^{*}\right)-0.0740\right)^{2}+\left(E\left(Q \mid \phi, \lambda^{*}\right)-1.3025\right)^{2} .
$$

All the above parameters are reported in table 4.

Table 4: Parameters Values for The ACM Model

\begin{tabular}{|c|c|c|c|c|}
\hline$\beta$ & $\sigma$ & $\delta$ & $\phi$ & $\lambda^{*}$ \\
\hline 0.95 & 6.2 & 0.04 & 1.8 & 0.6 \\
\hline
\end{tabular}

Table 5 reports the data and the model moments.

Note that correlations in table 5 also have the same sign as those in table 6 .

A comparison of model moments. - Table 6 reports moments of the data and of the various models; the moments were obtained using a pseudo-random sequence of $z$ 's of length 100,000.

\section{Appendix 2: Extensions}

\subsection{Research}

Because new seeds are proportional to capital in the model, seeds pile up in recessions, and this depresses $Q$ for a while after the recovery starts. If research or other resources 
Table 5: Unconditional Correlations in the Model and in the Data

\begin{tabular}{|c|c|c|c|c|c|c|c|}
\hline \multirow{2}{*}{\multicolumn{4}{|c|}{ Model }} & \multicolumn{4}{|c|}{ Data } \\
\hline & & & & & $s$ & $x$ & $Q$ \\
\hline$z$ & -0.58 & 0.45 & 0.94 & $z$ & -0.04 & 0.49 & 0.71 \\
\hline$s$ & & -0.08 & -0.60 & $s$ & & -0.11 & -0.19 \\
\hline$x$ & & & 0.14 & $x$ & & & 0.33 \\
\hline
\end{tabular}

Table 6: Unconditional Correlations in the Model (using 100000 random draws of $z$ )

\begin{tabular}{cccc} 
& $s$ & $x$ & $Q$ \\
\hline$z$ & -0.5630 & 0.6125 & 0.9390 \\
$s$ & & -0.3461 & -0.5197 \\
$x$ & & & 0.3135
\end{tabular}

are needed, fewer seeds will be created when $p$ is low. To see how it might work, let us change (3) to

$$
\text { new seeds }=\lambda R^{\varepsilon} k^{1-\varepsilon}
$$

so that (4) becomes

$$
S^{\prime}=\lambda R^{\varepsilon} k^{1-\varepsilon}+S-X
$$

and so that (5) becomes

$$
X \leq \lambda R^{\varepsilon} k^{1-\varepsilon}+S
$$

The planner's Bellman equation becomes

$v(k, S, z)=\max _{R \geq 0, X \leq \lambda R^{\varepsilon} k^{1-\varepsilon}+S}\left\{\frac{(z k-X-R)^{1-\sigma}}{1-\sigma}+\beta \int v\left(k+X, \lambda R^{\varepsilon} k^{1-\varepsilon}+S-X, z^{\prime}\right) d F\right\}$.

For $\sigma \neq 1, v$ is still of the form

$$
v(k, S, z)=w(s, z) k^{1-\sigma},
$$

where $w(s, z)=v(1, s, z)$, and where $w$ satisfies

$$
w(s, z)=\max _{(r, x) \in \Omega(s)}\left\{\frac{(z-x-r)^{1-\sigma}}{1-\sigma}+(1+x)^{1-\sigma} \beta \int w\left(\frac{\lambda r^{\varepsilon}+s-x}{1+x}, z^{\prime}\right) d F\right\}
$$

where

$$
r=\frac{R}{k}
$$


Table 7: Model moments

\begin{tabular}{|c|c|c|c|c|c|}
\hline \multirow[b]{2}{*}{ Moment } & \multirow[b]{2}{*}{ Data } & \multicolumn{4}{|c|}{ (No seed storage) (infinite seeds) } \\
\hline & & SDM & $\operatorname{SDM}(\gamma=1)$ & $\operatorname{SDM}\left(s_{0}=\infty\right)$ & $\mathrm{ACM}$ \\
\hline$E(z)$ & 0.37 & 0.367 & 0.367 & 0.368 & 0.368 \\
\hline$E(x)$ & 0.07 & 0.074 & 0.074 & 0.082 & 0.073 \\
\hline$E(s)$ & 0.002 & 0.007 & 0.000 & - & - \\
\hline$E(Q)$ & 1.30 & 1.303 & 1.316 & 1.000 & 1.301 \\
\hline$E(c)$ & 0.30 & 0.293 & 0.294 & 0.285 & 0.290 \\
\hline$\sigma(z)$ & 0.027 & 0.024 & 0.024 & 0.023 & 0.023 \\
\hline$\sigma(x)$ & 0.007 & 0.004 & 0.003 & 0.010 & 0.073 \\
\hline$\sigma(s)$ & 0.009 & 0.012 & 0.000 & - & - \\
\hline$\sigma(Q)$ & 0.566 & 0.302 & 0.299 & 0.000 & 0.069 \\
\hline$\sigma(c)$ & 0.020 & 0.021 & 0.022 & 0.014 & 1.000 \\
\hline
\end{tabular}

and

$$
\Omega(s)=\left\{(r, x) \mid x \leq s+\lambda r^{\varepsilon}\right\} .
$$

Since $\varepsilon<1, r$ will never be negative. If $z$ was firm specific and if seeds could not be stored, this version of the model would be close to Klette and Kortum (2004) and Lentz and Mortensen (2005).

The problem with this is that it introduces a Q-elastic supply of seeds, which will limit somewhat how much $\mathrm{Q}$ can rise in booms. In sum, it will produce less variation in $\mathrm{Q}$, but maybe a more realistic seeds.

\subsection{The deterministic Seeds model}

Suppose $z$ is a constant. Since $k$ does not depreciate, $x$ then equals the growth rate of $k$ and of $C$. Let's solve for the constant-growth rate that would obtain in the absence of the constraint (5). We shall call this the "desired" growth rate, $x^{d}$. Then $U^{\prime}\left(C_{t+1}\right) / U^{\prime}\left(C_{t}\right)=(1+x)^{-\sigma}$ and the effective discount factor is

$$
\hat{\beta} \equiv \beta(1+x)^{-\sigma} .
$$

An additional unit of capital produces $z$ units for ever, and so optimal investment leads to a Tobin's $Q$ of unity:

$$
Q \equiv\left(\frac{\hat{\beta}}{1-\hat{\beta}}\right) z=1
$$

Equations (52) and (53) can be solved for $x^{d}$ :

$$
1+x^{d}=(\beta[1+z])^{1 / \sigma} .
$$


The model collapses to the standard model if $s$ goes off to infinity. We seek parameter restrictions that will prevent this from happening. From (5),

$$
x_{t} \leq \min \left(z, \lambda+s_{t}\right)
$$

This, however, is a short-run constraint, that holds at each $t$. If $k$ were to grow faster than $\lambda, s_{t}$ would eventually become negative. To see this, combine (4) and (3) to get $S^{\prime}=S-X+\lambda k$ and, hence,

$$
s_{t+1}=\frac{\lambda+s_{t}-x_{t}}{1+x_{t}}
$$

It's easy to show that $\lambda$ is the maximal feasible long-run growth rate. Let $\varepsilon$ be a constant, and suppose that $x=\lambda+\varepsilon$. Then

Lemma 9 For all $s_{0} \geq 0$,

$$
\begin{array}{ll}
(i) & \varepsilon>0 \Longrightarrow s_{t} \rightarrow-\infty \\
(i i) & \varepsilon<0 \Longrightarrow s_{t} \rightarrow+\infty
\end{array}
$$

Proof. (i) Let $\varepsilon>0$. Then $s_{t+1}=\frac{\lambda+s_{t}-x}{1+x}=\frac{s_{t}-\varepsilon}{1+x}<s_{t}-\frac{\varepsilon}{1+x}$, so that $s_{t}<$ $s_{0}-\left(\frac{\varepsilon}{1+x}\right) t \rightarrow-\infty$. (ii) let $\varepsilon<0$. Then $s_{t+1}>s_{t}+\frac{|\varepsilon|}{1+x}$ so that $s_{t}>s_{0}+\frac{|\varepsilon|}{1+x} t \rightarrow+\infty$.

Desired growth exceeds $\lambda$ if

$$
[\beta(1+z)]^{1 / \sigma}>1+\lambda
$$

which is also when the seeds constraint binds in every period. High values of $z$ or $\beta$, and low values of $\sigma$ and $\lambda$ make it more likely that this inequality will hold. Tobin's $Q$ is just the present value of the marginal product of capital, $\Sigma_{t=1}^{\infty} \tilde{\beta}^{t} z$, i.e.,

$$
Q=\left(\frac{\tilde{\beta}}{1-\tilde{\beta}}\right) z, \quad \text { where } \tilde{\beta}=\beta(1+\lambda)^{-\sigma}>\beta\left(1+x^{d}\right)^{-\sigma}=\hat{\beta} .
$$

Values of $Q$ above unity arise because consumption growth is lower than it would be under $x^{d}$; the rate of interest is thus lower, and this raises the present value of income from capital above its cost.

The case $\sigma=1$. - From (54), the desired investment and growth rate $x$ is

$$
x^{d}(z)=\beta z-(1-\beta),
$$

and Tobin's $Q$ is

$$
Q(z)=\left\{\begin{array}{ll}
1 \quad & \text { if } x^{d}(z) \leq \lambda \\
\frac{\beta}{1+\lambda-\beta} z & \text { if } x^{d}(z)>\lambda
\end{array} .\right.
$$

The value of $z$ at which $x^{d}(z)=\lambda$ is $\frac{1}{\beta}(1+\lambda-\beta)$. Figure 12 plots $x^{d}(z)$ and $Q(z)$. Of course, $x=\min \left(\lambda, x^{d}[z]\right)$. 

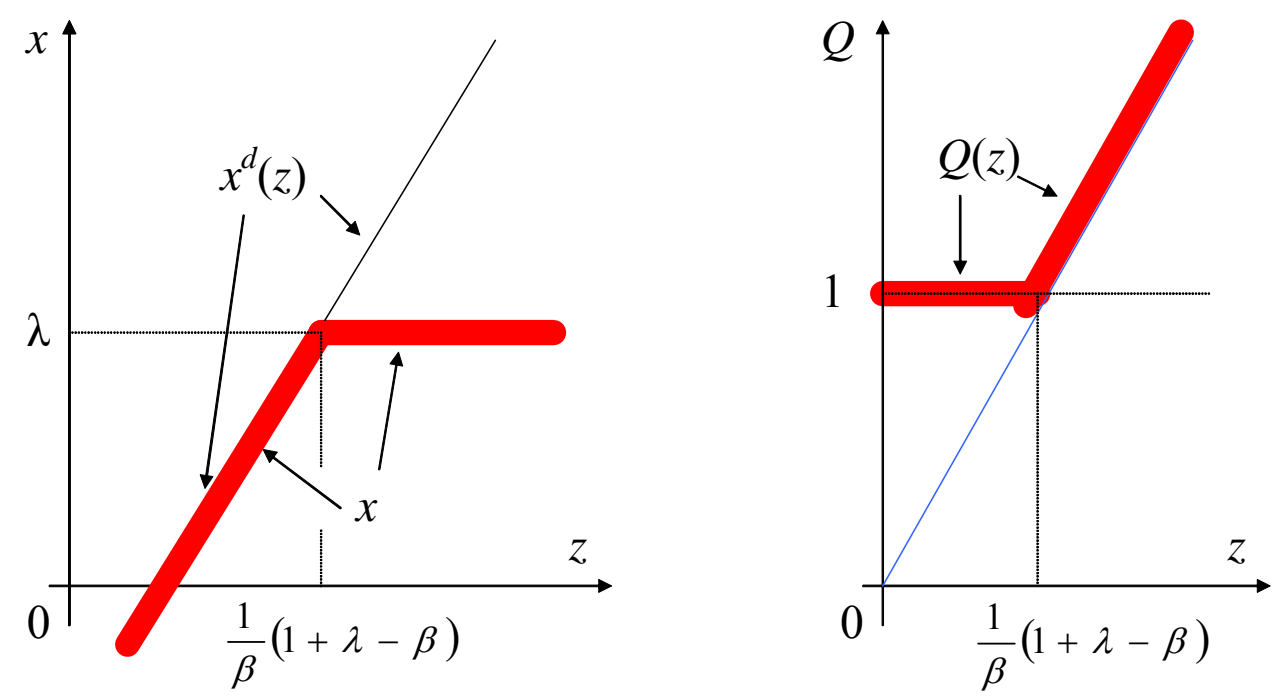

Figure 12: Comparative SteAdy States For $x$ And $q$ When $\sigma=1$.

\subsection{Transitional dynamics in the deterministic case}

We shall just set up the basics, but not carry out the analysis. The transitional dynamics are easier to analyze if time is continuous. If $\lambda$ is high enough, the model has no transitional dynamics because then seeds are a free good, an irrelevant byproduct of final-goods production. Transitional dynamics arise when desired growth exceeds $\lambda$, i.e., when (57) holds. Let $\left(k_{0}, S_{0}\right)$ be given, with $S_{0}>0$. Let preferences be

$$
\int_{0}^{\infty} \frac{1}{1-\sigma} e^{-\rho t} C_{t}^{1-\sigma} d t
$$

Output is

$$
z k=C+X
$$

the laws of motion are

$$
\dot{S}=\lambda k-X \quad \text { and } \quad \dot{k}=k+X
$$

and the seed constraint reads

$$
S \geq 0
$$

In the absence of the seed constraint "desired" growth would be $\frac{\dot{C}}{C}=\frac{\dot{k}}{k}=\frac{z-\rho}{\sigma}$. For transitions to occur we therefore need that

$$
\lambda<\frac{z-\rho}{\sigma}
$$

In this case, the seed constraint must eventually bind, from which point on we have $X=\lambda k$. 
Optimal growth.-This is a version of Hotelling's exhaustible-resources problem. The control is $X$ and the states are $(k, S)$. The Hamiltonian is

$$
\frac{(z k-X)^{1-\sigma}}{1-\sigma}+\mu X+p(\lambda k-X)+n S
$$

where $m$ is the shadow value of $S$ and $\mu$ is the shadow value of capital. The optimality conditions are

$$
\begin{aligned}
X & : \quad-(z k-X)^{-\sigma}-\mu-m=0 \\
k & : z(z k-X)^{-\sigma}+\lambda m=-\dot{\mu}+\rho \mu \\
S & : n=-\dot{m}+\rho m
\end{aligned}
$$

and the two constraints must hold.

The region $[0, T)$ where $S>0$.- Let $T$ be the date at which the transition ends. For $t \geq T, S_{t}=0$ and $X_{t}=\lambda k_{t}$. In this region, $n=0$ so that (60) implies

$$
m_{t}=m_{0} e^{\rho t} \quad \text { for } t<T \text {. }
$$

Substituting for $m_{t}$ and from (58) into (59) gives us

$$
\mu z+\lambda m_{0} e^{\rho t}=-\dot{\mu}+\rho \mu
$$

which is the differential equation

$$
\dot{\mu}=(\rho-z) \mu-\lambda m_{0} e^{\rho t}
$$

Now an equation of the form $\frac{d \mu}{d t}=A \mu+B e^{\rho t}$ has the solution $\mu=C_{1} e^{A t}+B \frac{e^{\rho t}}{\rho-A}$. Therefore

$$
\mu_{t}=C_{1} e^{(\rho-z) t}-\frac{\lambda m_{0}}{z} e^{\rho t}
$$

The region $[T, \infty)$.- Here all the multipliers are constant. In particular

$$
\mu=1+m \text {. }
$$

Tobin's Q.- Let Tobin's $Q$, defined here as the discounted marginal product of $k$ :

$$
Q=\int_{t}^{\infty} e^{-\rho(\tau-t)} \frac{U^{\prime}\left(C_{\tau}\right)}{U^{\prime}\left(C_{t}\right)} z d \tau
$$

This is the present value of a unit of capital. In the limit, consumption will grow at the rate $\lambda$ so that $\frac{U^{\prime}\left(C_{\tau}\right)}{U^{\prime}\left(C_{t}\right)}=e^{-\sigma \lambda(\tau-t)}$ and $Q$ will converge to

$$
Q_{\infty}=z \int_{t}^{\infty} e^{-(\rho+\sigma \lambda)(\tau-t)} d \tau=\frac{z}{\rho+\sigma \lambda}
$$

where the rate of interest is

$$
\rho+\sigma \lambda
$$

which is less than $z$ if $(57)$ holds, so that $Q_{\infty}>1$. But if (57) does not hold, then consumption grows at the rate $\frac{z-\rho}{\sigma}$ and $Q_{\infty}=1$. 


\section{Appendix 3: Proofs of differentiability}

This is the proof of Lemma 4. The complete proof is for the case of no depreciation.

I use subscripts to denote the state that a policy pertains to. Thus we have the accounting identities

$$
s_{s}^{\prime}=\frac{\lambda+s-x_{s}}{1+x_{s}} \quad \text { and } \quad s_{s+h}^{\prime}=\frac{\lambda+s+h-x_{s+h}}{1+x_{s+h}} .
$$

Variations.-We use (39) to figure out the feasible variations.

Variation $(i)$. - If we begin at state $s+h$, and if we want to end up at $s_{s}^{\prime}$, we need an investment of

$$
\begin{aligned}
\hat{x}\left(s_{s}^{\prime}, s+h\right) & =\frac{\lambda+s+h-\frac{\lambda+s-x_{s}}{1+x_{s}}}{1+\frac{\lambda+s-x_{s}}{1+x_{s}}}=\frac{\left(1+x_{s}\right)(\lambda+s+h)-\left(\lambda+s-x_{s}\right)}{1+x_{s}+\lambda+s-x_{s}} \\
& =\frac{\left(1+x_{s}\right) h+x_{s}(\lambda+s)+x_{s}}{1+\lambda+s} \\
& =x_{s}+h \frac{1+x_{s}}{1+\lambda+s} .
\end{aligned}
$$

Then

$$
A_{h} \equiv\left(\frac{1+\hat{x}}{1+x_{s}}\right)^{1-\sigma}=\left(1+\frac{h}{1+\lambda+s}\right)^{1-\sigma}
$$

and

$$
\hat{x}-x_{s}=h \frac{1+x_{s}}{1+\lambda+s} .
$$

Therefore

$$
\begin{aligned}
w(s+h, z) & \geq U\left(z-\hat{x}\left[s_{s}^{\prime}, s+h\right]\right)+\left(1+\hat{x}\left[s_{s}^{\prime}, s+h\right]\right)^{1-\sigma} \beta \int w\left(s_{s}^{\prime}, z^{\prime}\right) d F \\
& =U\left(z-\hat{x}\left[s_{s}^{\prime}, s+h\right]\right)+A_{h}\left(1+x_{s}\right)^{1-\sigma} \beta \int w\left(s_{s}^{\prime}, z^{\prime}\right) d F \\
& =U\left(z-\hat{x}\left[s_{s}^{\prime}, s+h\right]\right)+A_{h}\left(w(s, z)-U\left(z-x_{s}\right)\right)
\end{aligned}
$$

and

$$
\begin{aligned}
w(s+h, z)-w(s, z) & \geqslant U\left(z-\hat{x}\left[s_{s}^{\prime}, s+h\right]\right)-A_{h} U\left(c_{s}\right)+\left(A_{h}-1\right) w(s, z) \\
& =U\left(z-\hat{x}\left[s_{s}^{\prime}, s+h\right]\right)-U\left(c_{s}\right)+\left(A_{h}-1\right)\left(w(s, z)-U\left(c_{s}\right)\right) .
\end{aligned}
$$

Dividing both sides by $h$ and taking the limit as $h \searrow 0$ gives

$$
\begin{aligned}
\frac{d}{d s} w(s, z) & \geqslant-U^{\prime}\left(c_{s}\right) \lim _{h \searrow 0} \frac{\hat{x}-x_{s}}{h}+\lim _{h \searrow 0} \frac{\left(A_{h}-1\right)}{h}\left[w(s, z)-U\left(c_{s}\right)\right] \\
& =-U^{\prime}\left(c_{s}\right) \frac{1+x_{s}}{1+\lambda+s}+(1-\sigma) \frac{w(s, z)-U\left(c_{s}\right)}{1+\lambda+s} .
\end{aligned}
$$


because, by L'Hôpital's rule,

$$
\begin{aligned}
\lim _{h \searrow 0} \frac{\left(A_{h}-1\right)}{h} & =\lim _{h \searrow 0} \frac{d A_{h}}{d h}=\lim _{h \searrow 0} \frac{d}{d h}\left(1+\frac{h}{1+\lambda+s}\right)^{1-\sigma} \\
& =\frac{1-\sigma}{1+\lambda+s} \lim _{h \searrow 0}\left(1+\frac{h}{1+\lambda+s}\right)^{-\sigma} \\
& =\frac{1-\sigma}{1+\lambda+s}
\end{aligned}
$$

Variation 2: Start from $s$ and end at $s_{s+h}^{\prime} \cdots$

Variation (ii).- If we begin at state $s$, and if we want to end up at $s_{s+h}^{\prime}$, we need an investment of

$$
\begin{aligned}
\hat{x}\left(s_{s+h}^{\prime}, s\right) & =\frac{\lambda+s-\frac{\lambda+s+h-x_{s+h}}{1+x_{s+h}}}{1+\frac{\lambda+s+h-x_{s+h}}{1+x_{s+h}}}=\frac{\left(1+x_{s+h}\right)(\lambda+s)-\left(\lambda+s+h-x_{s+h}\right)}{1+x_{s+h}+\lambda+s+h-x_{s+h}} \\
& =\frac{x_{s+h}(\lambda+s)-\left(h-x_{s+h}\right)}{1+\lambda+s+h}=\frac{(1+\lambda+s) x_{s+h}-h}{1+\lambda+s+h} \\
& =\frac{(1+\lambda+s+h) x_{s+h}-h\left(1+x_{s+h}\right)}{1+\lambda+s+h} \\
& =x_{s+h}-\frac{h\left(1+x_{s+h}\right)}{1+\lambda+s+h} \\
& <x_{s+h}-\frac{h\left(1+x_{s}\right)}{1+\lambda+s+h}
\end{aligned}
$$

because by Corollary 2, $x$ is increasing in $s$. We shall also need the following implication of (62):

$$
B_{h} \equiv\left(\frac{1+\hat{x}}{1+x_{s+h}}\right)^{1-\sigma}=\left(1-\frac{h}{1+\lambda+s+h}\right)^{1-\sigma}
$$

Therefore

$$
\begin{aligned}
w(s, z) & \geq U(z-\hat{x})+(1+\hat{x})^{1-\sigma} \beta \int w\left(s_{s+h}^{\prime}, z^{\prime}\right) d F \\
& =U(z-\hat{x})+B_{h}\left(1+x_{s+h}\right)^{1-\sigma} \beta \int w\left(s_{s+h}^{\prime}, z^{\prime}\right) d F \\
& =U(z-\hat{x})-B_{h} U\left(z-x_{s+h}\right)+B_{h} w(s+h, z) .
\end{aligned}
$$

and therefore

$$
w(s, z)-w(s+h, z) \geq U(z-\hat{x})-B_{h} U\left(z-x_{s+h}\right)+\left(B_{h}-1\right) w(s+h, z),
$$


i.e.,

$$
\begin{aligned}
w(s+h, z)-w(s, z) & \leq B_{h} U\left(z-x_{s+h}\right)-U(z-\hat{x})+\left(1-B_{h}\right) w(s+h, z) \\
& =U\left(z-x_{s+h}\right)-U(z-\hat{x})+\left(1-B_{h}\right)\left[w(s+h, z)-U\left(c_{s}(65)\right)\right]
\end{aligned}
$$

Now, $\left[w(s+h, z)-U\left(z-x_{s+h}\right)\right]$ is Lipschitz in $h$ for every $z>0$. This is because it is bounded above by the increment in value when a unit of consumption is added in perpetuity, and the latter is bounded as long as $c>0$, i.e., as long as $z>0$ ). Now, by (63), $x_{s+h} \geq \hat{x}+\frac{h\left(1+x_{s}\right)}{1+\lambda+s+h}$ and therefore

$$
U\left(z-x_{s+h}\right)-U(z-\hat{x}) \leq U\left(z-\hat{x}+\frac{h\left(1+x_{s}\right)}{1+\lambda+s+h}\right)-U(z-\hat{x})
$$

Using the RHS of this expression to replace the first two terms on the RHS of 65) leaves the inequality in (65) undisturbed. Moreover, using L'Hôpital's rule as before,

$$
\lim _{h \searrow 0} \frac{1}{h}\left(1-B_{h}\right)\left[w(s+h, z)-U\left(c_{s+h}\right)\right]=\frac{1-\sigma}{1+\lambda+s}\left[w(s, z)-U\left(c_{s}\right)\right]
$$

Putting this all together,

$$
w_{s} \leq \frac{1}{1+\lambda+s}\left(U^{\prime}\left(c_{s}\right)\left(1+x_{s}\right)+(1-\sigma)\left[w(s, z)-U\left(c_{s}\right)\right]\right)
$$

Then (61) and (66) imply (14). To see this, (14) says (in this notation) that

$$
w_{s}=\frac{1}{1+\lambda+s}\left([1-\sigma] w-(1+z) U^{\prime}(c)\right)>0 .
$$

For them to be the same we would need that

$$
-(1+x) U^{\prime}+(1-\sigma)(w-U)=(1-\sigma) w-(1+z) U^{\prime},
$$

i.e.,

$$
-(1+x) U^{\prime}-(1-\sigma) U=-(1+z) U^{\prime}
$$

i.e.

$$
(1-\sigma) U=(z-x) U^{\prime}
$$

which is true because $z-x=c$, so that both sides of the equation equal $c^{1-\sigma}$. Therefore (61) and (66) imply (14).

\subsection{Notes on differentiability when $\delta$ and $\gamma$ are positive}

Let $\delta=$ depreciation of $k$ and let $\gamma$ be the depreciation of $S$. The laws of motion and the value are

$$
k^{\prime}=k(1-\delta)+X
$$




$$
S^{\prime}=(1-\gamma)(S+\lambda k-X)
$$

and

$v(k, S, z)=\max _{X \leq \lambda k+S}\left\{\frac{(z k-X)^{1-\sigma}}{1-\sigma}+\beta \int v\left(k[1-\delta]+X,(1-\gamma)(S+\lambda k-X), z^{\prime}\right) d F\right\}$.

Then

$$
s^{\prime}=\frac{S^{\prime}}{k} \frac{k}{k^{\prime}}=\frac{(1-\gamma)(s+\lambda-x)}{1-\delta+x}
$$

Alternatively,

$$
\hat{x}\left(s^{\prime}, s\right)=\frac{(1-\gamma)(\lambda+s)-(1-\delta) s^{\prime}}{1-\gamma+s^{\prime}} .
$$

The auxiliary Bellman equation is

$$
w(s, z)=\max _{x}\left\{\frac{(z-x)^{1-\sigma}}{1-\sigma}+(1-\delta+x)^{1-\sigma} \beta \int w\left(\frac{(1-\gamma)(s+\lambda-x)}{1-\delta+x}, z^{\prime}\right) d F\right\},
$$

Differentiation:

$$
w=\max _{s^{\prime}}\left\{\frac{(z-\hat{x})^{1-\sigma}}{1-\sigma}+(1-\delta+\hat{x})^{1-\sigma} \beta \int w\left(s^{\prime}, z^{\prime}\right) d F\right\}
$$

where $\hat{x}$ is defined in (72). Take the derivative w.r.t. $s$ :

$$
\begin{aligned}
w_{s} & =\frac{1-\gamma}{1-\gamma+s^{\prime}}\left\{-(z-\hat{x})^{-\sigma}+(1-\sigma)(1-\delta+\hat{x})^{-\sigma} \beta \int w\left(s^{\prime}, z^{\prime}\right) d F\right\} \\
& =\frac{1-\gamma}{1-\gamma+s^{\prime}}\left\{-U^{\prime}+\frac{1-\sigma}{1-\delta+\hat{x}}(w-U)\right\} \\
& =\frac{1}{1+\frac{s+\lambda-x}{1-\delta+x}}\left\{-U^{\prime}+\frac{1-\sigma}{1-\delta+\hat{x}}(w-U)\right\} \quad\left(\text { using }[71] \text { for } \frac{s^{\prime}}{1-\gamma}\right) \\
& =\frac{1-\delta+\hat{x}}{1-\delta+\lambda+s}\left\{-U^{\prime}+\frac{1-\sigma}{1-\delta+\hat{x}}(w-U)\right\}
\end{aligned}
$$

When $\gamma=\delta=0$, does this become $w_{s}=\frac{1}{1+\lambda+s}\left([1-\sigma] w-(1+z) U^{\prime}(c)\right)$ ? For that to be true we would need

$$
-(1+\hat{x}) U^{\prime}+(1-\sigma)(w-U)=(1-\sigma) w-(1+z) U
$$

But this is the same as (67), and so it holds. 